\title{
Vasos litúrgicos para el Bautismo y la Santa Unción, dos sacramentos de vida
}

\author{
María Luisa Martín Ansón \\ Universidad Autónoma de Madrid \\ Departamento de Historia y Teoría del Arte \\ luisa.martin@uam.es
}

\begin{abstract}
RESUMEN
El Bautismo y la Santa Unción marcan dos momentos cruciales de la existencia del cristiano; su iniciación en la fe y su tránsito a la vida futura. La administración de ambos sacramentos conlleva un conjunto de prácticas rituales, de marcado simbolismo, para cuya celebración son necesarios, además de un marco arquitectónico adecuado, una serie de objetos litúrgicos, a veces poco analizados. En la mayoría de las ocasiones, la atención se ha centrado en el estudio de piezas espectaculares utilizadas en distintas ceremonias, incluidas éstas, y han quedado en un segundo plano otras imprescindibles pero, con frecuencia, de menor riqueza, que centrarán nuestro estudio en función del desarrollo de la liturgia.
\end{abstract}

Palabras clave: Bautismo, Unción, Viático, Crismera, Pila.

\section{Liturgical Vessels for Baptism and the Holy Unction, Two Sacraments of Life}

\begin{abstract}
Baptism and Holy Unction are two mile stones in the life of a Christian as by means of these sacraments he is accepted as a member of the Christian Church, and prepared for his transit to eternal life. Both require ceremonial observances of specific symbolical content and they call for an appropriate architectural scenery and a number of liturgical objects which not always have been duly analysed. Interest has mostly focused on gorgeous items used in various ceremonies, as well as on the ceremonies themselves. However, other fundamental elements have been left aside. These elements will be the target of our work related to the liturgical development of the rites.
\end{abstract}

Key words: Baptism, Unction, Viaticum, Chrismatory, Basin. 
La administración de sacramentos como el Bautismo y la Santa Unción marca de modo especial la vida del cristiano. El primero supone el rito de iniciación en la fe y de agregación a la Iglesia de Cristo. En palabras de Éric Palazzo ${ }^{1}$, el bautismo es el sacramento por excelencia de la integración en la comunidad de los fieles y en la estructura social. Mediante él, se ingresa en la comunidad religiosa recibiendo el necesario impulso para el desarrollo de una vida terrenal conforme a un ideal de vida eterna. A través de la Extremaunción, se puede acceder a la curación de la enfermedad y, en su caso, se posibilita el tránsito con éxito a la vida futura. Ya Dionisio el Areopagita, al tratar del bautismo en el segundo capítulo de la Jerarquía Eclesiástica dice así:

"la muerte y la sepultura están bastante bien representadas por la inmersión completa del cuerpo en el agua bautismal. Cuando en el bautismo tres veces se sumerge en el agua y tres veces se retira de ella al catecúmeno, se le hace comprender por esta enseñanza figurativa que recuerda los tres días y las tres noches que Jesús, el autor de la vida, pasó en la tumba después de su muerte"2.

Sin embargo, España y en realidad toda la Península Ibérica, conoció la inmersión única que subrayaba la unidad sustancial de la Trinidad, y se piensa que los primeros testimonios de la fórmula bautismal se remontan a San Ildefonso, a mediados del s. VII ${ }^{3}$. El santo toledano en su tratado De Cognitione Baptismi ${ }^{4}$, después de haber descrito la renuncia bautismal, continúa según el encargo del Señor (Mateo 28, 19), diciendo: "Id, enseñad a todas las naciones, bautizándolas en el nombre del Padre y del Hijo y del Espíritu Santo", añadiendo el sacerdote: "para que tengas la vida eterna, el hombre es sumergido en las aguas". El texto supone una fórmula trinitaria pero es necesario resaltar que el rito visigótico bautismal, como sabemos por Martín de Braga y por la carta de San Gregorio Magno, reproducida en el canon 6 del IV Concilio de Toledo (633), solo comporta una inmersión en lugar de las tres colocadas inmediatamente después de cada una de las preguntas trinitarias. Esta particularidad se da en España debida a la reacción anti-arriana.

La participación en ambos sacramentos lleva implícitas una serie de prácticas litúrgicas que, si bien con una finalidad similar, no siempre son idénticas en todos los lugares y, como es obvio, han ido variando con el transcurso del tiempo. Aunque nuestro propósito es analizar algunos de los objetos utilizados en las ceremonias rituales,

1 E. PALAZZO, Liturgie et société au Moyen Âge, París, 2000, pp. 42-43.

2 L'abbé E. VAN DRIVAL, "Étude sur les Fonts Baptismaux", Revue de l'Art Chrétien, $1^{\text {er }}$ artículo (1858), pp. 18-25. El autor habla de Dionisio el Areopagita pero, sin duda, se refiere a Pseudo-Dionisio el Areopagita. Ver: PSEUDO DIONISIO AREOPAGITA, Obras completas: los nombres de Dios. Jerarquía celeste. Jerarquía eclesiástica. Teología mística. Cartas varias, Madrid, 2002.

3 Ver al respecto, entre otros: Dom P. DE PUNIET, "Baptême", Dictionnaire d'archeologie chrétienne et de liturgie, II, 1, París, 1910, cols. 336-344; P. DE CLERCK, "Les origines de la formule baptismale", Mélanges offerts à Pierre-Marie Gy, París, 1990, pp. 199-213; J. VIVES, Concilios visigóticos, BarcelonaMadrid, 1963, pp. 191-192; y P.-M. GY, "La formule 'Je te baptise' (Et ego te bautizo)", Mélanges offerts a J.J. von Allmen, Ginebra, 1982, pp. 65-72.

4 C. SÁNCHEZ MONTEALEGRE, "Liturgia bautismal y San Ildefonso", Crónica mozárabe: Boletín Informativo de la ilustre Comunidad Mozárabe de Toledo, 41 (1996), pp. 4-12. 
no podemos prescindir de ciertos datos que nos ayuden a entender mejor el sentido de ambos sacramentos. Por ello, nos limitaremos a plantear una serie de cuestiones previas, en la confianza de que nos sirvan para una mejor comprensión.

Para los sacerdotes de la Edad Media todos los sacramentos son útiles para la salvación y es preciso que los miembros de la iglesia se aprovechen de ellos. Por ello, será necesario acompañarlos con acciones evangelizadoras. De forma general se puede decir que los últimos paganos pasaron al cristianismo antes del fin de la Antigüedad, y la Edad Media determinó que, para acceder al bautismo, todos debían conocer y utilizar el Pater Noster, el Credo, y el Símbolo (la Fórmula) de los Apóstoles. Era responsabilidad de los padres, padrinos y madrinas su enseñanza.

A partir de mediados del s. XIII, los teólogos proponen dos o tres criterios, de tal modo que los fieles conocen todos el signo de la cruz, y por él, al Padre, al Hijo y al Espíritu Santo; por las fiestas del año conocen los principales misterios de Cristo: su Natividad, su Pasión y su Resurrección y saben, al menos, que cuando se confiesan obtienen el perdón de sus pecados. Además, Santo Tomás y todos los medievales estiman que el niño desde la edad de la razón es capaz de tener fe personal y responsabilidad moral y desde la pubertad tiene el derecho a casarse sacramentalmente con o sin consentimiento de sus padres. Solo a partir del s. XVII se desarrolla la idea de que los niños son otra cosa que adultos todavía pequeños ${ }^{5}$.

\section{El bautismo}

La tradición patrística remonta la institución bautismal a la predicación de Juan Bautista, relatada por todos los evangelistas, en la cual indicaba, aun sin nombrarlo, a Jesús como autor de un futuro bautismo ${ }^{6}$. El propio Jesús lo recibió de sus manos en el río Jordán (Mateo 3, 13-17), consagrándolo como principio de regeneración espiritual y como medio para entrar a formar parte del reino de Dios, y, estableció la fórmula oficial referida a la Trinidad cuando envió a sus apóstoles a bautizar a las gentes (Mateo 18, 19, Juan 3, 5-6) ${ }^{7}$.

Se escogió como fecha apropiada para su administración la madrugada del Sábado Santo al Domingo de Resurrección, quedando en segundo lugar la festividad de Pentecostés. Después de un período de formación y la inscripción de los catecúmenos para recibir el bautismo, previa superación de una prueba en la que pusieran de manifiesto sus conocimientos, avalados por los padrinos, el neófito estaba preparado para recibir el sacramento. Tras la vigilia del Sábado, los catecúmenos se dirigían en procesión hasta el baptisterio, siendo precedidos por el obispo, los sacerdotes y el Cirio Pascual. Una vez dentro del baptisterio y reunidos alrededor de la piscina bautismal, lo primero era la bendición del agua. A continuación hacían, en público, los

\footnotetext{
5 P.-M. GY, "Évangélisation et sacrements au Moyen Âge", Humanisme et foi chrétienne. Mélanges scientifiques du centenaire de l'Institut catholique de Paris, París, 1976, pp. 565-572.

6 "Yo ciertamente os bautizo en agua para penitencia; más el que viene en pos de mí es más fuerte que yo, cuyas sandalias no soy digno de atar. El os bautizará en el Espíritu Santo y en el fuego".

7 M. RIGHETTI, Historia de la Liturgia, vol. II, Madrid, 1961, p. 190.
} 
ritos de renuncia al diablo y la profesión de fe. Posteriormente, su cuerpo se ungía totalmente con el Santo Óleo y se procedía al descenso en la piscina, donde el sacerdote derramaba por tres veces el agua sobre su cabeza pronunciando el nombre de las Tres Personas. Al abandonar la piscina el "recién nacido" a la fe era ungido con el Crisma y cubierto con una túnica blanca -in albis - que simbolizaba la pureza del alma y que debería mantener durante los ocho días siguientes.

Después de la unción crismal, el sacerdote da al recién bautizado o al padrino que lo representa una vela encendida, acompañando el rito con una fórmula, que se inspira, como toda la ceremonia, en la parábola evangélica de las vírgenes prudentes. Los bautizados escuchaban en seguida la lectura del evangelio del lavatorio (Juan 13, 4-11), después el obispo ayudado por los sacerdotes, les lavaba los pies. La lectura supone un púlpito fijo o móvil que no menciona ningún texto. Para el lavatorio de los pies propiamente dicho, se puede pensar que el ceremonial era calcado al del relato evangélico: el obispo, provisto de un barreño, se desplazaba ante los bautizados sentados, pero otros escenarios son evidentemente posibles. Finalmente, tiene lugar la confirmación que Ambrosio llama signaculum spirituale, y no consignatio, que es el termino más frecuente. La imparte el obispo mediante la imposición de las manos y la unción del crisma sobre la frente. Aparentemente la confirmación se da en el baptisterio ya que el primer texto que menciona un consignatorium no es anterior al s. IX. Se atribuye la construcción de esta sala a Juan III, obispo de Nápoles de principios de la séptima centuria ${ }^{8}$.

Terminadas estas ceremonias, todo estaba dispuesto para la solemne celebración de la misa y la administración de la Eucaristía a los nuevos bautizados. Esta práctica estaba todavía en vigor en el s. XIII. Así pues, las capillas bautismales estaban dotadas de altares, a veces ricamente decorados. Por ejemplo, se sabe que, entre otros, el Papa Simacus 9 , mandó hacer sobre la pila sagrada de la basílica de San Pedro, un oratorio de plata dedicado a la Santa Cruz, una confesio y una cruz de oro ${ }^{10}$. Según otros autores, se organizaba la procesión a la iglesia, donde proseguía la misa en la que comulgaban los neófitos junto con los demás asistentes, incluidos los niños que, según dice San Agustín, en edad en que todavía no podían con pan, lo hacían solo bajo la especie de vino; práctica habitual también cuando los domingos asistían a misa en brazos de sus madres ${ }^{11}$.

El ritual del bautismo parece, sin duda, ser el más estable de la liturgia cristiana. El origen de esta estabilidad se basa ya en algunos pasajes bíblicos. San Pablo en su epístola a los Efesios declara: un solo Señor, una sola fe, un solo bautismo. En el texto sagrado se encuentran los tres elementos fundamentales que constituyen el bautismo

8 La aparición de una sala especial parece unida a la evolución del rito bautismal que se produce en el Ordo $X I$, compuesto en Roma en el s. VII: J.-CH. PICARD, "Ce que les textes nous apprennent sur les équipements et le mobilier liturgique nécessaires pour le baptême dans le sud de la Gaule et l'Italie du Nord”, Actes du XI Congrès International d'Archéologie Chrétienne, vol. II, Roma, 1989, pp. 1451-1474 y 1465- 1466.

9 El Papa Simacus sucedió al Papa Anastasio muerto en 498. A. SEVESTRE, Dictionnaire de Patrologie, ou Repertoire historique bibliographique, 1835, cols. 1379-1384.

10 L'abbé E. VAN DRIVAL “Étude sur les Fonts Baptismaux”, Revue de l'Art Chrétien, 4 artículo (1858), pp. 204-216.

11 J. PIJUÁN, La liturgia bautismal en la España Romano-Visigoda, Toledo, 1981, pp. 55 y 83-100. 
cristiano: el recuerdo del bautismo de Juan Bautista; el bautismo hecho en el nombre del Señor y la intervención de Pablo que realiza la integración de los fieles en la comunidad. A pesar de esta solidez, lo que sabemos del ritual del bautismo muestra que, dentro de un marco común, existe cierta diversidad, de una iglesia local a otra, en el número y el orden de los ritos que le acompañan, así como en el detalle de las fórmulas pronunciadas ${ }^{12}$.

\section{Simbolismo}

Al igual que el resto de los sacramentos y las prácticas litúrgicas que conllevan, los aquí referenciados están inmersos dentro del contexto simbolista que impregna, de modo general, las prácticas religiosas. Así, el bautismo sacramental tiene su propia significación y el agua corriente que lava el cuerpo del neófito debe designar en la mente de Jesús la limpieza completa del alma, de la culpa y su renacimiento espiritual. San Pablo señala en el rito litúrgico de la inmersión y de la emersión el símbolo de la muerte y de la resurrección de Cristo, en correspondencia con la renovación interior del hombre, regenerado del pecado a la gracia (Romanos, 6-4). Claramente, pues, puede deducirse la vinculación entre la vida, la muerte y la resurrección, con lo cual bautismo y santa unción aparecen indisolublemente unidos en la trayectoria vital del hombre ${ }^{13}$.

La propia palabra bautismo derivada del vocablo griego bapto o Baptizo, que significa lavar o sumergir, nos indica que se trata de una práctica en la que el agua es el elemento primordial, a ser posible corriente. Las razones que llevaron a la Iglesia a elegir el agua como materia, según los escolásticos, se debieron a considerarla signo de purificación y de fecundidad, además de principio de crecimiento para el alma regenerada. Junto al agua, la luz será otro elemento clave de valor simbólico en la ceremonia. El inicio del cortejo por parte del obispo portando el Cirio Pascual, símbolo de Cristo resucitado, se ve incrementado por la entrega de la vela encendida por parte del sacerdote al recién bautizado o, en su caso, al padrino. Este hecho se relaciona con la abundante iluminación que desde el s. IV, especialmente en Oriente, se encendía en

12 J.-CH. PICARD, op. cit., 1989, p. 1451.

13 En este punto conviene recordar que la inversión del Alfa y la Omega que aparecen, a veces, tanto en las pilas bautismales como en inscripciones sepulcrales, pueden tener también un especial valor simbólico. Si Alfa significa "el principio" y Omega "el fin” y ambas se aplican en el Apocalipsis a Dios como principio y fin del universo, concepto ya expresado por Isaías, el hecho de escribir Omega-Alfa significaría la voluntad de expresar el paso del fin al principio, es decir de la muerte a la vida. Este doble camino de alfa a omega y de omega a alfa, aparece repetidamente en el pensamiento de algunos Padres de la Iglesia tales como Clemente Alejandrino, Tertuliano o Paulino de Nola. Aplicando este sentido a los fieles individuales tendríamos la explicación del sentido liberador que se ha querido dar al cambio de orden de las letras apocalípticas donde se verifica el paso de muerte a vida, mediante el agua. M.A. ALONSO SÁNCHEZ, "Crismones con Omega Alfa en España", IX Symposium de Prehistoria i Arqueologia Peninsular. II Reunió d'Arqueologia Cristiana Hispànica, Barcelona, 1982, pp. 279-302, y "Pilas bautismales con Omega-Alfa", II Symposium de Arqueología Soriana, vol. 2, Soria, 1992, pp. 1131-1142; y M.I. MEDIERO VELASCO, "El bautismo y las pilas bautismales", Revista de Arqueología, 308 (2006), pp. 30-39. 
la noche de Pascua en señal de alegría por el bautismo (la illuminatio) de los neófitos, a la cual se asociaba con las luces ${ }^{14}$.

La degustación de la sal bendita, símbolo de la sabiduría divina, ya manifestado por Cristo respecto a sus apóstoles, es considerada por San Agustín como un sacramental y la pone en relación con la propia comunión eucarística. Además, los antiguos le atribuían gran valor apotropeútico para neutralizar el influjo de los espíritus malignos. En cuanto a la leche y la miel, hay que decir que de aquella se hace ya mención en la primera Carta de San Pedro (2, 1-3), si no como rito, al menos como símbolo bautismal:

"Rechazad, por tanto, toda malicia y todo engaño, hipocresías, envidias y toda clase de maledicencias. Como niños recién nacidos, desead la leche espiritual pura, a fin de que, por ella crezcáis para la salvación, si es que habéis gustado que el Señor es bueno".

La pureza interior, fruto del lavatorio bautismal, tenía su expresión cubriendo al neófito con una vestidura blanca; lo mismo que, según parece, hicieron en las iniciaciones de sus adeptos los cultos mistéricos antiguos. Los primeros testimonios ciertos de este rito se encuentran hacia la mitad del s. IV. Parece derivar de la costumbre de secar el cuerpo del neófito con un paño de lino blanco. Algunos creen descubrir en esto una alusión a las visiones del Apocalipsis de San Juan, donde aparece la cándida muchedumbre de los elegidos alrededor del trono del Cordero. Pero, el color blanco de aquellas vestiduras es clarísimamente simbólico; entre los antiguos era el color propio de los días de fiesta y de las ceremonias del culto porque era símbolo de la pureza ritual ${ }^{15}$. El vestido, a menudo, va bordado y sobre la capucha lleva una corona de color rojo ${ }^{16}$.

Este significado inherente a los propios sacramentos, se ve reforzado por los gestos que acompañan a la ceremonia, tales como las insuflaciones usadas en el bautismo y la inhalación que se lleva a cabo durante la consagración de los óleos y en la bendición de las fuentes. El soplo en el rostro en el bautismo simboliza la huida del demonio del alma, y el alentar sobre el agua y sobre el crisma significa la comunicación de la virtud santificadora a estos elementos hecha por el ministro sagrado. La imposición de las manos sobre la cabeza y la señal de la cruz en la frente es una invocación a Dios para que, iluminando al candidato, lo prepare a la fe. Los propios catecúmenos recibían la insalivación mediante la cual un sacerdote, mojando el dedo con saliva, tocaba sus labios y sus oídos para significar que debían estar abiertos en adelante a las alabanzas y a la voz de Cristo. En la ceremonia del apertio, el obispo toca las orejas y las narices del futuro bautizado diciendo: Effeta, es decir ábrete.

14 M. RIGHETTI, op. cit., 1961, II, p. 220. El rito de la bendición del agua consta de tres partes: exorcismo, infusión del aceite en forma de cruz y bendición. San Ambrosio conmemora los lumina neophitomm splendida, que estos llevaban en la procesión de la fuente al altar.

15 Ibid., p. 221.

16 Curiosamente, también después de producirse el óbito, los familiares, al amortajar el cadáver, cubrían el rostro con un paño blanco a modo de sudario (Cantiga 62 bis, Códice de Florencia de las Cantigas de Santa María). 
Con el Effeta se han abierto sus sentidos para oír y expresar su voluntad; con la unción del óleo sobre el pecho y la espalda, el candidato ha llegado al momento crítico de la lucha con Satanás, porque dentro de poco renegará de él solemnemente para darse definitivamente a Jesucristo. Para salvaguardar la intimidad, la unción de las mujeres la hacían las diaconisas. Después de la unción total se procedía a la renuncia de Satanás ${ }^{17}$. No obstante, si es verdad que los símbolos -agua, luz, leche, miel, sal, crisma, vestiduras blancas, etc.- permanecen invariables, es cierto que cambian su inserción temporal y dinámica en el rito y su colocación en el espacio, así como la percepción de los significados que se les han atribuido ${ }^{18}$.

\section{Tipos de bautismo}

Para todos los maestros de la Edad Media el sacramento consiste en el baño con agua y la invocación trinitaria que le acompaña. Respecto al primer punto, se podía bautizar por inmersión o por infusión. En los primeros siglos, el bautismo era administrado en un río o incluso en el impluvium de una casa particular. En las catacumbas se dispusieron cubicula para este efecto. Al decir de Jansen ${ }^{19}$, la idea de la piscina en los baptisterios había sido sugerida por el impluvium; la piscina rodeada de un parapeto y coronada por un ciborium, cede paso a una cuba, hundida en la tierra o colocada directamente sobre el suelo, a veces incluso sobre un pie poco elevado. Según apunta, se servían también de sarcófagos, bañeras antiguas, capiteles y columnas vaciadas e incluso toneles de madera cuyo recuerdo queda en los fustes anillados de las fuentes de época románica. El soporte empieza a ser cada vez más importante y pronto las pilas bautismales toman el aspecto de los ejemplares que se han conservado.

Desde el s. IV se construyeron baptisterios separados de la iglesia donde el sacramento se administraba a los adultos por el obispo una o dos veces al año. La práctica lleva a administrar el bautismo más a menudo durante el año y el porcentaje de niños aumenta entre los bautizados. Esto implica la celebración cada vez más frecuente de las ceremonias bautismales en ausencia del obispo quien interviene en un segundo momento para administrar la confirmación. De este modo, la iniciación cristiana deja de formar un conjunto homogéneo y se compondrá del bautismo administrado cada vez más por sacerdotes y la confirmación que será exclusiva de la liturgia episcopal ${ }^{20}$.

La existencia de la piscina bautismal era imprescindible en el caso del bautismo por inmersión que estaba limitado a la parte inferior de las piernas, sumergidas en el agua hasta casi las rodillas. Así, el candidato desciende a la piscina, cuyo fondo está por debajo del suelo del baptisterio. Esto responde a un valor simbólico, según se ha señalado, pues el rito del bautismo está marcado por la imagen pauliniana del bautismo como descenso a la tumba, después resurrección. En algunas piscinas este

17 M. RIGHETTI, op. cit., 1961, II, p. 210.

18 R. SALVARINI, "Liturgia e partecipazione nei riti del battesimo tra X e XII secolo. I 'casi' del fonte de Chiavenna e della vasca di Fidenza”, Liturgia e partecipazione. Atti del Convegno di Studio, Padua, 2009, pp. 46-78.

19 A. JANSEN, Art chrétien jusqu'à la fin du Moyen Âge, Bruselas, 1964, pp. 46-48.

20 E. PALAZZO, op. cit., 2000, p. 44. 
trayecto se materializaba por la presencia de escaleras y si eran poco profundas el fiel se acostaba como un muerto en su tumba (Fig. 1).

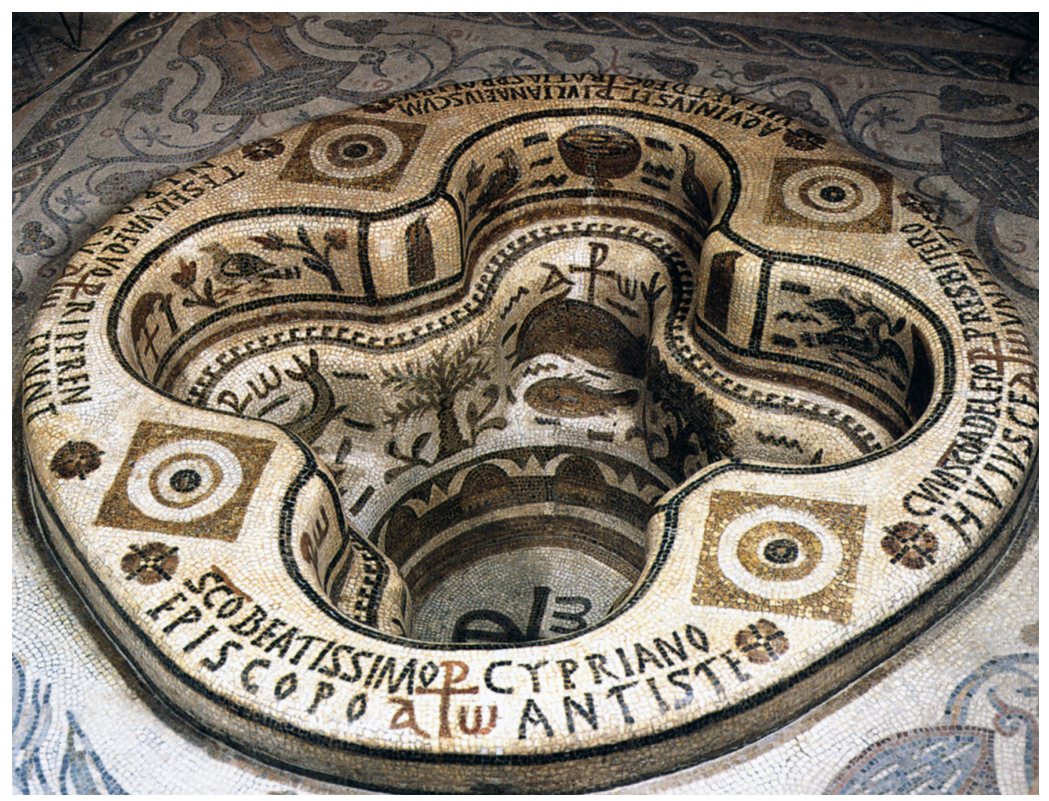

Fig. 1. Piscina bautismal de Kelibia, s. VI. Museo Nacional de El Bardo, Túnez.

Para sumergirse en la piscina era necesario estar completamente desnudo, según lo subraya San Ambrosio, algo que puede resultar sorprendente cuando se observa que el espacio era compartido por personas de distinto sexo. Incluso en Milán, los bautizados permanecían desnudos mientras que el obispo les lavaba los pies, algo que parece insólito puesto que la desnudez no era materialmente necesaria para el cumplimiento del rito. ${ }^{21}$ Junto con los vestidos, el bautizando debía quitarse todos sus accesorios aún de simple adorno, como amuletos, anillos, pendientes, etc., donde, según la concepción antigua, el demonio podía esconder una insidia ${ }^{22}$.

Una vez más las Cantigas se convierten en una fuente importante para conocer estas prácticas en las distintas modalidades de bautismo. Por solo citar algunas nos referiremos a la Cantiga 89f (Códice Rico, El Escorial) donde podemos observar a una mujer judía con sus dos hijos, todos ellos desnudos dentro de una pila bautismal. Se unen el bautismo por inmersión con el de infusión, pues un sacerdote vierte con un jarro el agua sobre ellos. Además, observamos también cómo un diácono tiene en su mano el vaso con la sal y un acólito las ampollas de los Santos Óleos y la candela que después tomará la recién bautizada. En su forma de bautismo por infusión la Cantiga 46f (Códice Rico, El Escorial) presenta a un moro, desnudo, arrodillado sobre unas

21 J.-CH. PICARD, op. cit., 1989, p. 1465.

22 La Traditio, en efecto, advierte que las mujeres no pueden presentarse al bautismo con joyas y collares de ningún género y deben deshacer las trenzas de sus cabellos. 
gradas. El sacerdote vierte sobre su cabeza el agua con un jarro de dos asas. Entre las personas que asisten a la ceremonia, uno tiene las ampollas de los Santos Óleos y otro sujeta en sus manos el vestido que después usará el neófito, mientras una mujer sostiene la candela (Fig. 2).

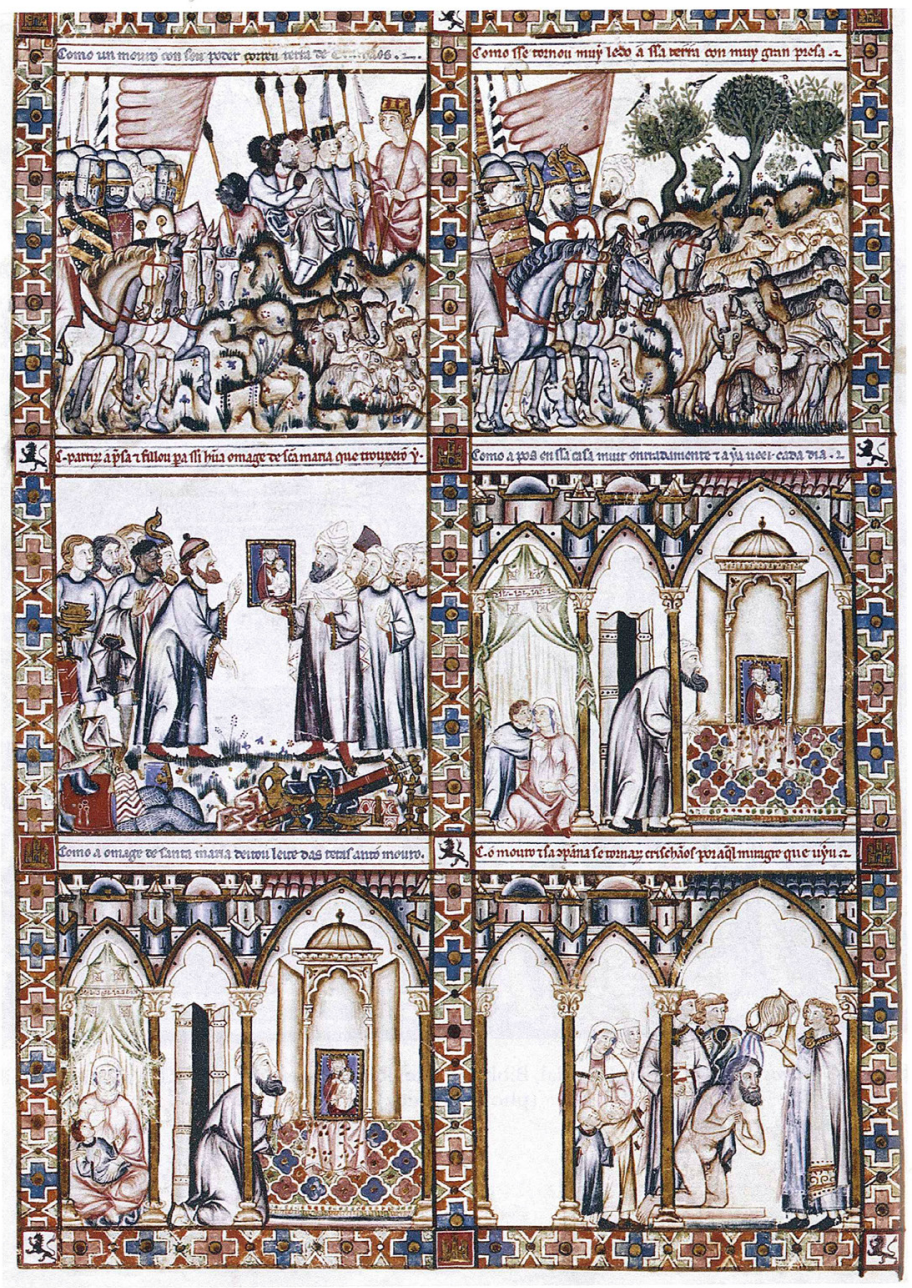

Fig. 2. "Conversión de un moro", Cantiga 46, Códice Rico de las Cantigas de Santa María (RBME, Ms. T-I-1).

No obstante, para evitar la mezcla de sexos, la Traditio indica que se bautice en primer lugar a los niños, después a los hombres y finalmente a las mujeres. Del mismo modo, se han apuntado otras soluciones como el hecho de que los hombres esperasen a que los niños, acompañados de sus padrinos y madrinas, hubieran cumplido todos los ritos y hubieran recibido la ropa blanca antes de entrar a su vez en el baptisterio, 
y las mujeres esperarían, de la misma manera, que terminaran los hombres, sin descartar la posibilidad de que también se creara un segundo baptisterio reservado para ellas $^{23}$.

Respecto al bautismo de los niños parece que ya en la segunda mitad del s. VI o primera parte del s. VII había un ritual organizado exclusivamente para ellos. Así se deduce de la encuesta sobre el bautismo hecha por Carlomagno en 812 a los metropolitanos de su Imperio. Incluso, veinticinco años después, un capitular impuesto por el propio emperador en Sajonia, prescribe, bajo penas de pesadas multas, que todos los niños sean bautizados Infra annum. Así pues, a partir de la época carolingia la práctica general era bautizar a los niños lo más tarde a la edad de un año. Incluso, dada la elevada mortandad infantil, se estableció la costumbre de bautizar a todos los bebés en los días siguientes al nacimiento ${ }^{24}$. Del s. VIII al X los niños de un año eran puestos de pie en cubas verticales donde se sujetaban con la ayuda de los padrinos que los sostenían y a los recién nacidos se les sumergía horizontalmente. Este hecho acentuó la práctica del bautismo por infusión y lo convirtió en el rito predominante y después único. También puede detectarse en el paso de la historia el modo de la aspersión, o sea de lanzar con hisopo u otro instrumento parecido gotas de agua sobre uno o varios bautizados. Las tres formas eran igualmente admitidas ${ }^{25}$.

\section{El baptisterio: el mobiliario y los objetos litúrgicos}

En el mundo medieval, especialmente a lo largo de la Alta Edad Media, la evolución de las formas arquitectónicas del baptisterio está muy condicionada por las prácticas litúrgicas. Incluso, como se ha apuntado con anterioridad, en algunos baptisterios la presencia de un altar atestigua la multifuncionalidad del espacio; baptisterio y oratorio. Tanto su ubicación, como su propia estructura están, además, dotadas del correspondiente simbolismo ${ }^{26}$. El mobiliario en ellos es realmente escaso; el púlpito y la silla episcopal no aparecen como piezas obligatorias y lo único realmente imprescindible es la piscina, o en su caso, la pila bautismal. Junto a estas piezas muebles será necesario aludir a diversos objetos necesarios para la ejecución de un ritual que se va complicando con el paso del tiempo, unos específicos y otros de uso compartido con otras celebraciones.

23 J.-CH. PICARD, op. cit., 1989, p. 1458.

24 P.-M. GY, op. cit., 1976, p. 566, n. 11: del s. VIII al X los niños parecen haber sido bautizados a la edad de un año en cubas verticales donde podían estar de pie con la ayuda de los padrinos que los sostenían; solo en el s. XI se propaga la costumbre de regenerar a los nuevos nacidos algunos días después de su nacimiento. Ver también: A. GUERREAU-JALABERT, "Spiritus et caritas. Le baptême dans la societé medievale", La Parenté Spirituelle, París, 1995, pp. 133-203.

25 J. HORTAL, Los sacramentos de la Iglesia en su dimensión canónico-pastoral, Bogotá, 1994, p. 55.

26 C. GODOY FERNÁNDEZ, "A los pies del Templo. Espacios litúrgicos en contraposición al altar: una revisión”, Sacralidad y Arqueología, XXI (2004), pp. 473-489. Así, por ejemplo, muchos baptisterios se colocan junto a las puertas de entrada, significando con ello que es el paso previo y requisito indispensable para poder ingresar en la comunidad de los fieles y participar de los misterios de la salvación, mientras en España una de las características distintivas es su ubicación a los pies de la iglesia. 


\section{Las pilas bautismales}

Sin duda las pilas bautismales cobran un protagonismo especial y, si bien la tipología variará poco, siendo una síntesis de formas anteriores, incluirán una rica iconografía y se realizarán en los más diversos materiales, que suelen identificarse con el ámbito geográfico en que se producen; madera, piedra, metales, alabastro, mármol, cerámica, etc. Entre los metales encontramos gran variedad, desde el oro y la plata ${ }^{27}$, hasta el latón, el cobre, el peltre, el plomo o diversas aleaciones. No obstante, el uso de la piedra será lo más habitual. Solo en el caso de que la piedra sea muy porosa, los concilios y los sínodos autorizan a revestirla en el interior de plomo o cobre estañado ${ }^{28}$. Esta ley fue numerosas veces promulgada y, todavía en el s. XIII, Durando de Mende la registra formalmente ${ }^{29}$. A partir de esta centuria van provistas de una tapa pues, en 1236, San Edmundo obligó a cubrirlas con una tapa de madera, cerrada con llave o con sello de cera, mientras no fueran utilizadas.

El empleo del metal sin duda gozó de gran relevancia en la Dinanderie ${ }^{30}$, donde todavía en los siglos XIII-XIV perviven las formas románicas. Desde el s. XIII se divide la cuba en dos compartimentos, de los cuales uno contiene el agua bautismal y el otro recibe el agua que había caído sobre la cabeza del nuevo bautizado. A veces, era una segunda cuba más pequeña la que servía para esto. La cubierta de las fuentes en metal iba ricamente decorada, teniendo su mayor desarrollo hacia fines del s. XIV, pero sobre todo en el XV. Adopta generalmente la forma de una pirámide o de una flecha, análoga a la de las torres eucarísticas. Su peso llegaba a ser tan considerable que era necesario para levantarla recurrir a una polea.

Entre las pilas bautismales metálicas merece consideración destacada la conservada en la iglesia de San Bartolomé de Lieja, obra de Rainiero de Huy, del que se conoce su oficio gracias a una carta de la iglesia de Notre Dame de Huy, firmada por el obispo Albero I, en que Reinerus avrfiex aparece como testigo. Fue encargada por el abad Hillin (1107-1118) para su iglesia de Notre Dame aux Fonts, según un texto contemporáneo conocido como Chronicon rythmicum Leodiense, que proporciona una precisa descripción, en la que se menciona también la cubierta, hoy perdida, que representaba a los profetas y los apóstoles ${ }^{31}$ (Fig. 3).

El plomo tendrá asimismo su protagonismo en la elaboración de pilas bautismales en Inglaterra, aunque en Francia también se produjeron, muy parecidas a las inglesas. Los primeros ejemplos ingleses conocidos integran un grupo de cubas de plomo de origen romano-británico datadas hacia el s. IV, pero, desgraciadamente, no se ha

\footnotetext{
27 El Liber Pontificalis (314-335) menciona la pila de plata de veinte libras de peso que el emperador Constantino donó a Ostia.

28 El primer concilio de Lérida (546) en tiempos del rey ostrogodo Teudis, acordó y dictó que, de allí en adelante, las pilas bautismales tenían que ser de piedra, aunque eso no fue obstáculo para el uso de otros materiales.

29 DURANDO DE MENDE, Rational des divins offices, Lib. VI.

30 La bibliografía al respecto, como se puede suponer, es muy extensa. Por ello solo remitimos a una síntesis realizada por J. TOUSSAINT, Art du laiton. Dinanderie, Namur, 2005.

31 J.L. KUPPER, "Les fonts baptismaux de l'église Notre Dame à Liege", Feuillets de la Cathédrale de Liège, 16-17 (1994), pp. 1-12.
} 
podido establecer una continuidad con las pilas del período románico, puesto que muchas debieron ser fundidas. Los artesanos usaban un mismo diseño varias veces, y las pilas muestran esa repetición de motivos decorativos en cada panel. Entre ellas figuran la de la iglesia de San Agustín, Brooklands (Kent) o la de Saint Evroult de Monfort, c. $1200^{32}$.

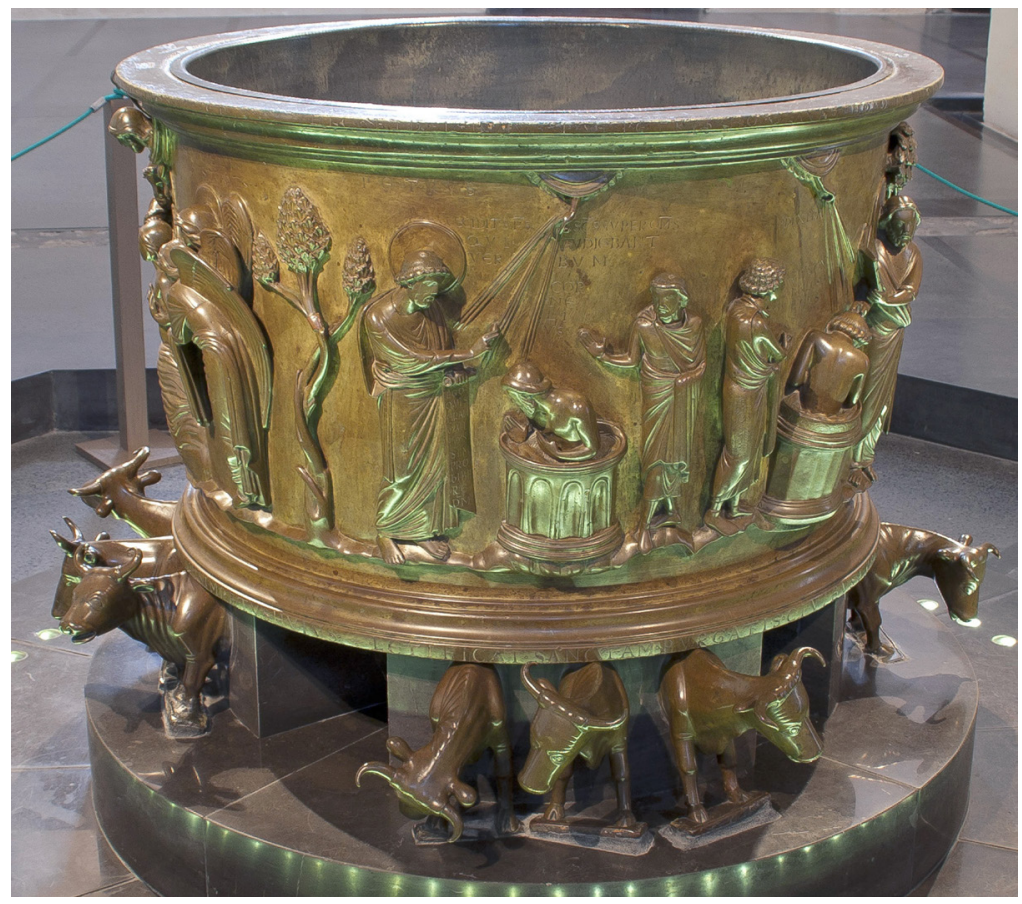

Fig. 3. Rainiero de Huy, Pila bautismal, 1107-1118. Iglesia de San Bartolomé, Lieja.

En el ámbito español son numerosas las pilas bautismales conservadas pero, desgraciadamente, el arte del metal no parece estar presente, por lo que básicamente deberemos hablar de obras en piedra, en cerámica, etc. Frecuentemente, ilustran con sus propias representaciones algunos aspectos del origen, la ceremonia y el ritual del mismo sacramento para cuya administración sirve. Así, la ceremonia del bautismo de los adultos sigue siendo motivo de representación hasta fechas muy avanzadas del mundo medieval, aun cuando desde hacía tiempo se había impuesto el bautismo de los niños. Tal es el caso, por ejemplo, de las pilas de Itero Seco y Osornillo; con

32 M.A. TORRES ALZU, "Plúmbeas I. Las pilas románicas de plomo en Inglaterra”, Románico. Revista de Amigos del Románico, 5 (2007), pp. 40-47, y "Plúmbeas II. Los trabajos de los meses y los signos del zodíaco en las pilas románicas de plomo de Brookland y Saint Évroult-de-Monfort”, Románico. Revista de Amigos del Románico, 6 (2008), pp. 32-41. Las pilas plúmbeas inglesas se fabrican generalmente por el método del vaciado y fundición en moldes horizontales de varias piezas o paneles; una vez terminados los paneles se refinaba el trabajo con talla posterior, y se soldaban para formar la copa de la pila sobre una base redonda también de plomo, soldaduras que pueden verse claramente hoy día en la copa de la pila. 
cortejo en Colmenares de Ojeda (Fig. 4), o con la presencia de la paloma del Espíritu Santo asistiendo a la ascensión del alma, en Santa María la Nueva de Zamora ${ }^{33}$. La pervivencia de este tipo de bautismo fue especialmente acusada en el mundo hispánico que contó con importantes comunidades judías y musulmanas ${ }^{34}$.

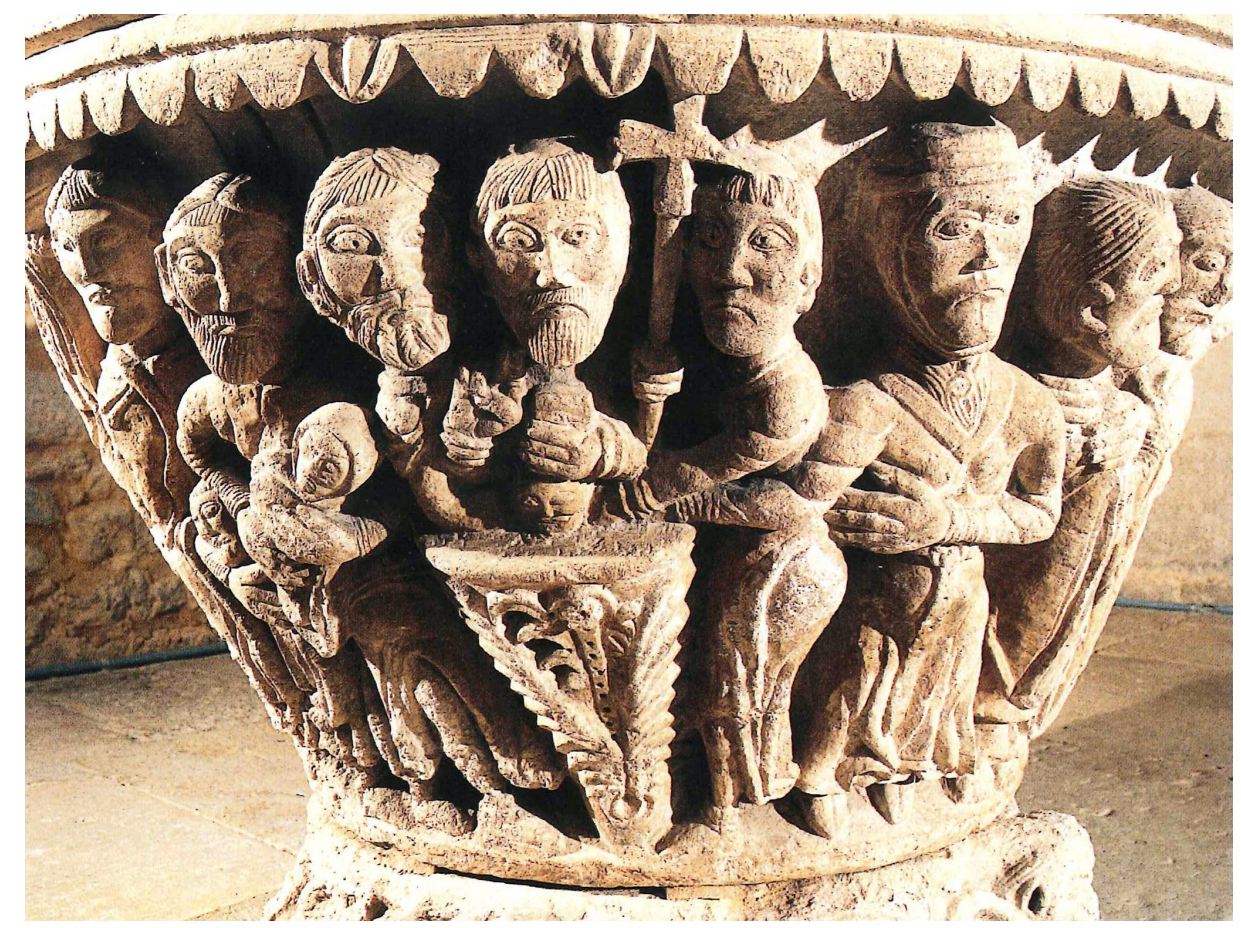

Fig. 4. Pila bautismal, segunda mitad del s. XII. Iglesia de San Fructuoso, Colmenares de Ojeda, Palencia.

Curioso es el caso de la pila bautismal de Santa María de Retortillo (Burgos) donde se representan los recipientes destinados a la conservación y utilización de los líquidos bautismales: dos vasos y una ampolla de panza abultada para los Santos Óleos, con que se ungía al neófito antes y después del bautismo, y una jarra de las utilizadas para la triple infusión del agua bautismal sobre la cabeza del mismo. Por su parte, la pila de Cillamayor (Castillo de Ampudia, Palencia) recoge la escena de la consagración de la pila bautismal, uno de los ritos más antiguos, al parecer ya practicado por las comunidades cristianas de Cartago y Roma hacia el 200. A los exorcismos les seguía la inmersión del cirio pascual por tres veces o del Lignum Crucis, como sig-

33 G. BILBAO LÓPEZ, "La representación del bautismo de los adultos en las pilas románicas de Itero Seco y Osornillo", Boletín de la Institución Tello Téllez de Meneses, 67 (1996), pp. 77-88; J.L. HERNANDO GARRIDO, "Las pilas bautismales románicas en Castilla y León: consideraciones sobre su iconografía", Mobiliario y ajuar litúrgico en las iglesias románicas, Aguilar de Campoo, 2011, pp. 149- 202.

34 ALFONSO X EL SABIO, Partida I, Título IV, Ley XVIII. 
nos de la Luz de Cristo ${ }^{35}$. Un diácono sujeta en una mano el hisopo utilizado en esta ceremonia mientras alarga el otro brazo señalando una representación de la Jerusalén Celeste $^{36}$. La ceremonia de la bendición de las aguas está recogida, asimismo, en la pila de Valdeande (Burgos). En este caso, se observan un sacerdote y varios diáconos que actúan en torno a la pila portando cruces y sacramentarios ${ }^{37}$.

\section{Los Vasa Sacra y los Vasa non Sacra}

Del mismo modo, formando parte del mobiliario litúrgico, encontramos una serie de objetos imprescindibles para el desarrollo ceremonial, entre los que habría que mencionar el acetre, las crismeras, cruces, ampollas, hisopo, etc., en fin, lo que para algunos autores se conoce como "vasos sagrados secundarios" 38 . Otros, por su parte, prefieren hacer una distinción entre los vasa sacra y los vasa non sacra ${ }^{39}$, incluyendo en el primer apartado los vasos sagrados que sirven para la comunión con el pan y el vino; cáliz, patena, píxide y ciborio, así como las vinagreras que contienen el agua y el vino. Estos objetos eran consagrados o bendecidos antes de su uso pues entraban en contacto con los elementos sagrados de la Eucaristía. Hasta fines del s. X solo los vasos sagrados, un pequeño relicario y un evangeliario estaban autorizados sobre el altar. Después, la evolución de la propia liturgia, con tendencia a la teatralidad, la solemnidad, la riqueza, etc. fue introduciendo modificaciones ${ }^{40}$. Conforme a las nuevas prescripciones, los vasa non sacra poco a poco se admitieron sobre los altares de la Europa continental, primero las cruces de altar y los candelabros, después los otros

35 Este rito conservado en algunas tradiciones orientales y en Hispania, es descrito por San Ildefonso en su De Cognitione Baptismi, CIX. J. CAMPOS (ed.), El conocimiento del Bautismo. El camino del desierto, Madrid, 1971, pp. 341-342. Guillermo Durando, al igual que de otros muchos, también habla de él: W. DURANDUS, The Symbolism of Churches and Church Ornaments. A translation of the First Book of the Rationale Divinorum Officiorum, edición de J. Mason Neale, B.A. y B. Webb, B.A., Nueva York, 1893, Cap. VIII. Según las Constituciones Apostólicas (VII, 43), después de signar el agua con la cruz, el sacerdote la divide con su mano y la lanza a las cuatro esquinas de la tierra. Esto significa el bautizo de todas las naciones. Luego respira sobre el agua y sumerge el cirio pascual en ella. Entonces vacía en el agua, primero el óleo de los catecúmenos y luego el crisma sagrado, y por último ambos óleos santos juntos, pronunciando rezos adecuados.

36 G. BILBAO LÓPEZ, op. cit., 1996, pp. 79-82; J.L. HERNANDO GARRIDO, op. cit., 2011. Consagración de la pila bautismal por medio de un diácono portando un hisopo, o cruces, sacramentarios y jarritas, en Renedo de Valdivia, Cillamayor, Valdeande y Gumiel de Mercado.

37 M.J. MARTÍNEZ MARTÍNEZ, "Valdeande. Iglesia de San Pedro Apóstol", Enciclopedia del Románico en Castilla y León. Burgos. IV, Aguilar de Campoo, p. 2901.

38 Dom G. MARIA, "Los Vasos Sagrados secundarios: Vinajeras y crismeras", Germinans germinabit, 2011. http://infocatolica.com/blog/germinans.php/1112021059-de-capitulo-44-los-vasos-sagr-2011 (acceso 27/2/2013).

3939 M. BRAMER SOLHAUG, "Les émaux limousins en Norvège. Caractéristiques, diffusion et transformations”, L'Euvre de Limoges et sa diffusion. Trésors, objets, collections, Rennes, 2011, pp. 55-72.

40 Así, por ejemplo, a comienzos del s. XIV, el Consuetudinario de la catedral de Mende entre los objetos destacados en la ceremonia de consagración del crisma señala los candelabros, el bastón de chantre (bordo) y del sacristán (virga), los barreños, las ampollas para el santo crisma, y, de modo especial, las cruces que son las que tienen el carácter más precioso; la cruz de plata, crux argentea, y la cruz de cristal, crux cristalli, que se citan a propósito de las procesiones. M.-T. GOUSSET, "Le Coutumier de la sacristie de la Cathédrale de Mende et les Arts Liturgiques", Guillaume Durand Évêque de Mende (v.1230-1296). Canoniste, liturgiste et homme politique. Actes de la Table Ronde du C.N.R.S., Mende, 1990, pp. 207-228. 
objetos no consagrados, tales como incensarios, aguamaniles para el rito del lavatorio de las manos y las crismeras o vasos de los santos óleos, si bien estas innovaciones no se produjeron en todos los sitios al mismo tiempo.

Una cierta unificación concedió validez y categoría a la mayoría de ellos, teniendo en cuenta que su funcionalidad era más amplia y formaban parte del conjunto de objetos de uso litúrgico de amplio espectro. Los materiales utilizados en su ejecución son variados y en ello tiene mucho que ver la riqueza del templo al que pertenecen. No obstante, en la mayoría de las ocasiones se eligen los metales lo que, por otro lado, no es en absoluto sorprendente, pues es sobradamente conocido su empleo, además de por la suntuosidad que infieren a las piezas, por el propio valor de símbolo de que están dotados al igual que las piedras preciosas, etc., que los enriquecen ${ }^{41}$. Las noticias más tempranas conocidas del uso de recipientes de metal en el servicio de la iglesia datan de los siglos III y IV. El Liber Pontificalis menciona, entre otras, como piezas usadas por el Papa Silvestre: una escudilla de plata de diez libras destinada a recibir el crisma en los bautismos y confirmaciones y una vasija bautismal de plata de veinte libras ${ }^{42}$.

\section{Los Santos Óleos y las Crismeras}

Imprescindibles para la administración de distintos sacramentos, entre ellos el bautismo y la santa unción, son los Santos Óleos. Se pueden considerar tres tipos: el Óleo de los Catecúmenos, usado en los que se están preparando para recibir el bautismo; el Santo Crisma, utilizado para las ordenaciones sacerdotales, confirmaciones y bautizos; y el Óleo de los Enfermos, usado en la Extremaunción ${ }^{43}$.

La ceremonia de consagración de los Santos Óleos, con vistas a la bendición de la fuente bautismal y la confirmación de los neófitos en la noche de Pascua, se llevaba a cabo en la liturgia del Jueves Santo. No obstante, es difícil precisar cuándo se comenzó a bendecir conjuntamente los tres óleos litúrgicos y a fijar el rito en dicho día. Especial significado en la ceremonia de bendición de los Óleos alcanzaba la procesión solemne organizada para el traslado de las ampollas del crisma y del óleo de los catecúmenos de la sacristía al altar, y viceversa. Participan en ella los sacerdotes,

41 M.L. MARTÍN ANSÓN, "El ajuar litúrgico de las iglesias románicas: objetos para el culto", Mobiliario litúrgico en las iglesias románicas, Aguilar de Campoo, 2011, p. 203-249.

42 B. KLEINSCHMIDT, "Metalwork in the Service of the Church", Catholic Encyclopedia, vol. 10, Nueva York, 1911. http://www.newadvent.org/cathen/10218a.htm.

43 El primero u oleum exorcistatum era consagrado por el obispo con una simple oración, después de haber practicado el exorcismo. Consta de aceite de oliva y crisma y sirve para ungir algunas partes del cuerpo de los futuros bautizados, antes de recibir la unción con el santo crisma, o bien las manos del sacerdote en el momento de su ordenación. El Chrisma se compone de aceite de oliva y de bálsamo. Se sirven de él en la administración del bautismo, de la confirmación, del orden y en la consagración de los soberanos, así como en la consagración de cálices y patenas, en la de iglesias y altares, y en la bendición de campanas y fuentes bautismales. E. RUPIN, L'Euvre de Limoges, París, 1890 (ed. 1977), pp. 443-446, n. 1. El tercero, el oleum infirmorum, se utilizaba únicamente para ungir a los moribundos, cuando recibían el sacramento de la Santa Unción. Encuentra su fórmula más antigua de bendición en la Traditio de San Hipólito. El obispo la recita en voz baja sobre la ampolla del óleo. 
los diáconos y los subdiáconos asistentes a la misa; se llevan las luces y el incienso y durante el trayecto se cantan los versus, atribuidos a Venancio Fortunato ${ }^{44}$.

Los Óleos así consagrados se guardaban en distintos recipientes conocidos genéricamente como crismeras, cuyas formas han ido evolucionando. Según Van Drival ${ }^{45}$ la capilla bautismal debía estar provista de un armario o tabernáculo con la inscripción Olea Sacra, convenientemente decorado, que guardaba el vaso del Santo Crisma, el del aceite de los catecúmenos, el de la sal, el libro llamado Ritual, el capillo de cristianar o ropa blanca, etc. Los vasos debían ser de plata, o al menos de estaño fino, y bastante anchos para que el ministro del sacramento pudiera meter fácilmente el pulgar para hacer las unciones. La inscripción CHR debía ir grabada sobre el que contenía el Santo Crisma y la inscripción CATH, sobre el del aceite de los catecúmenos. Además de estos dos vasos debe haber un tercero de la misma materia y tamaño, destinado a contener uno más pequeño con la sal bendecida. Este último puede ser en plata, en estaño o en madera, tendrá su propia cubierta y podrá extraerse fácilmente de aquel en que está contenido. Estos tres vasos deben estar unidos formando un triángulo con una cubierta única dividida en tres compartimentos y solidamente fijada. En dos de los compartimentos de esta cubierta irán las inscripciones correspondientes. Estos compartimentos deben estar huecos para meter los trozos de guata que han servido para las unciones y que, más tarde, serán quemados y arrojados a la piscina. El conjunto de los tres vasos se guardará en una caja de madera recubierta de cuero con adornos en oro, especialmente sobre la cubierta. El interior estará forrado de seda blanca. Ahora bien, la mayoría de los autores consultados no recogen la presencia del vaso que contenía la sal, sino tres recipientes para tres óleos distintos.

Respecto a su forma, al parecer, el vaso usado en la Antigüedad para custodiar el santo crisma presentaba forma de patena y se conocía como patena chrismalis. Posteriormente, se guardó en ampollas o en pequeños frascos llamados cresmier, cresmeau o chremier, colocados en un vaso único provisto de tres compartimentos distintos. Esta disposición era necesaria pues cada uno de los tres aceites no sirve en las mismas ceremonias. A menudo el aceite de los enfermos se llevaba lejos y, por ello, era preciso buscar el medio de destacar cada uno para el sacramento especial para el que debía servir. Para evitar confusión, pues el aceite de los catecúmenos y el de los enfermos solo difieren por la bendición apropiada para cada uno de ellos, y no por la sustancia, se coloca a menudo encima de la cubierta del pequeño frasco que los contiene, la letra $\mathrm{O}$ para indicar el de los catecúmenos, la letra $\mathrm{C}$ para el Santo Crisma, la letra I para el de los enfermos. Las ampollas encerradas en las cajas con los santos óleos eran a menudo de vidrio. A veces se encuentran en estaño y en plata. El conjunto se suele integrar en un pabellón de tres torres, a veces contenidas en una misma de mayor tamaño ${ }^{46}$.

44 M. RIGHETTI, op. cit., 1961, I, pp. 252-253. Audi iudex mortuorum, con el estribillo O Redemptor, sume carmen.

45 L'abbé E. VAN DRIVAL, op. cit., 1858, $4^{\circ}$ artículo, p. 205. Se basa en la obra de San Carlos Borromeo De la construction et de l'ameublement des églises, que él reeditó. Ver también X. BARBIER DE MONTAULT, Traité Pratique de la Construction, de l'ameublement et de la décoration des églises, París, 1878.

46 E. RUPIN, op. cit., 1977, pp. 443-446. 
Del mismo modo, se destaca inicialmente la forma de paloma, recipiente que se conservaba colgado en el baptisterio, suspendido por encima de las piscinas, para las unciones del bautismo y la confirmación. El Concilio de Constantinopla en 536 habla de esta costumbre. Dicha forma había sido sugerida por el episodio evangélico del bautismo de Cristo, durante el cual el Espíritu Santo había aleteado sobre él en forma de paloma. El uso de estas debe ser antiquísimo ya que Tertuliano alude a ellas $^{47}$, siendo bastante comunes en los siglos V y VI en las iglesias tanto de oriente como de occidente. Sabemos que en el año 468 el papa Hilario donó una de oro al baptisterio lateranense ${ }^{48}$. Su proximidad a las palomas que, de modo análogo, suspendían la Eucaristía por encima del altar, es más que evidente, pudiendo establecer una estrecha relación entre ambos tipos de vasos destinados a resaltar, incluso por su ubicación en las dependencias eclesiásticas, tanto la Eucaristía como el papel salvífico de los Santos Óleos. Ya, en su momento, J. Corblet ${ }^{49}$ recordaba que los neófitos recibían la comunión inmediatamente después del bautismo, y que la Eucaristía debía reservarse para este uso en los amplios baptisterios donde se encontraban a menudo varios altares. Del mismo modo, los Santos Óleos instalados sobre un pie elevado, al modo de un cáliz o de un relicario, eran transportados en procesión y expuestos a la veneración de los fieles, pues, después de la Eucaristía nada es más honrado que los Santos Óleos.

También para su conservación se servían de ampollas de terracota o de vidrio de uso común en las iglesias. Optato de Mileto hace alusión a un vaso de tal género, lleno de crisma, que los herejes donatistas tiraron por la ventana sin que se rompie$\mathrm{se}^{50}$. Así pues, durante la Edad Media, junto a las palomas crismales, se usaron ampollas de plata y estaño (chrismatorium, chrismarium, phialae...) e incluso cuernos de animales fijos sobre una base, o también vasos de cristal montados a la manera de píxide. Tal es el chrismatorium del tesoro de San Waast, en Praga que servía para la consagración de los reyes de Bohemia.

Aunque los vasos o ampollas nos son conocidos por los textos desde el s. V, solo a principios del s. XIII aparecen menciones de recipientes destinados a guardarlos, de los que únicamente se conocen una veintena. Suelen presentar diversas estructuras siendo frecuentes los pequeños cofres rectangulares con cubierta en forma de pirámide truncada coronada por una bola. Tal es el caso de la caja para los Santos Óleos del primer cuarto del s. XIII que se conserva en el tesoro de la iglesia parroquial de Saint

47 Q. SETTIMII FLORENTIS TERTULLIANI, De Baptismo, Turín, 1960, p. 14.

48 Recordemos, al respecto, el suceso que tuvo lugar en el momento del bautismo del rey Clodoveo por San Remigio, en Reims, en 496. Cuando al llegar al baptisterio el santo arzobispo comprobó que no había en él crisma para la unción, de pronto apareció en el recinto una paloma llevando en su pico una crismera de la que el prelado tomó el óleo necesario para ungir al catecúmeno. Esa crismera, después de numerosas vicisitudes, se piensa que es la conservada actualmente en la catedral de Reims y con su crisma se ungía a los reyes de Francia. En este caso, la paloma lleva en el pico la crismera, mientras las palomas eucarísticas solían llevar en el pico una píxide.

49 L'abbé J. CORBLET, "Essai historique et liturgique sur les ciboires et la réserve de 1'Eucharistie", Revue de l'Art Chrétien, $8^{\circ}$ artículo: "Ciboires en forme de colombe" (1858), pp. 388-394.

50 G. MARIA, op. cit., 2011. 
Viance (Fig. 5) ${ }^{51}$. En ocasiones están provistos de tres receptáculos pero, otras veces, no tienen mas que dos o incluso uno solo (para las administraciones). Los recipientes están o bien yuxtapuestos sobre un pequeño plato o bien encerrados en una pequeña caja en forma de edículo. Si no hay más que un recipiente, la crismera adopta a menudo la estructura de una torre ${ }^{52}$.

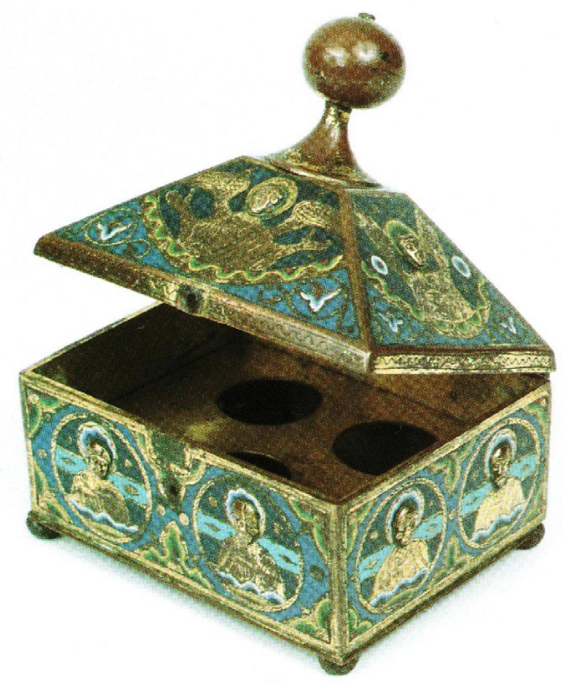

Fig. 5. Caja de los Santos Óleos, primer cuarto del s. XIII. Tesoro de la iglesia parroquial de Saint Viance, Correze.

La forma de pequeña ánfora, que podemos observar en el s. VI en la ampolla de Monza, estuvo vigente durante mucho tiempo gozando de especial interés en la corona de Castilla desde el s. XV. Así encontramos una crismera con la marca de Toledo, correspondiente a la época de los Reyes Católicos y otra, de similares características en el Victoria and Albert Museum de Londres publicada por Oman. La O que figura en el anverso seguramente se refiere al Óleo para el que estaba destinada. Dotada de un pie lobulado y alto astil de planta exagonal es la caja de Crismeras de Daroca (antes de 1504). Con tapa piramidal muestra el interior dividido transversalmente en

51 C. ARMINJON et al., Émaux Limousins du Moyen Âge. Correze, Creuse, Haute-Vienne, Limoges, 1995, p. 43 ; S. CAUDRON, "Boites aux saintes huiles", Corpus des Émaux Méridionaux. L'Apogée 11901215, II, París, 2011. pp. 242-243. Guardaba los Santos Óleos contenidos en tres ampollas desaparecidas. Está decorada en sus cuatro caras con dos figuras de apóstoles cada una, con cabezas añadidas aunque individualizadas, inscritos en busto en medallones. La cubierta presenta en cada vertiente un busto de ángel con las alas desplegadas.

52 A. JANSEN, op. cit., 1964, p. 45. Tal es el caso de una crismera de plata fundida, cincelada y parcialmente dorada provista de dos punzones de Lovaina y un pequeño punzón onomástico M o JP (Joos Pauwels el Joven), de la segunda mitad del s. XV. La torre cilíndrica reposa sobre tres leones sentados, y se adorna con un canelón y anillos. Está coronada por un techo cónico grabado de pizarras y bordeado de pequeñas almenas. Culmina en una pequeña esfera sobre la que se encuentra una cruz patada. En otras ocasiones presenta forma de edículo con tejado a doble vertiente adornado con imbricaciones. En la parte anterior se encuentran tres medallones con las letras O C I (Oleum Catechumorum et Infirmorum). 
tres partes mediante chapas planas ${ }^{53}$. Según se ha destacado con anterioridad debía tener un uso procesional.

Especial interés adquieren, asimismo, los Cálices Bautismales cuya finalidad era dar de beber a los recién bautizados la leche y la miel, como a niños recién nacidos. Alude a ello el Liber Pontificalis a propósito de Inocencio I (†417), que regaló cálices "ad baptismum III, pensantes singulos lib. II" 54 . Otros objetos utilizados, comunes a distintas ceremonias, serán los Cálices Ministeriales para dar la comunión después del bautismo; los jarros bautismales, generalmente provistos de dos asas y realizados en metal, tal como hemos señalado en algunas miniaturas de las Cantigas; la campanilla, cuyo uso hay que diferenciar de la campana ${ }^{55}$, que junto con las esquilas y los cascabeles, en la Edad Media, recibían la denominación de tintinnabulum, en alusión a su sonido más claro y menos potente. Tenían como finalidad ahuyentar a los malos espíritus y se utilizaban en numerosos momentos como, por ejemplo, el traslado del viático a los enfermos.

Del mismo modo, el acetre y el hisopo se emplean en numerosas ocasiones. Por lo que aquí respecta, debemos destacar su uso en el bautismo según el rito de aspersión, que solía reservarse para enfermos y cuando el sacramento se administraba a multitud de neófitos, como es el caso de bautizos masivos a moros y hebreos en tiempos de la Reconquista. Esta ceremonia se puede observar en el sotabanco del retablo mayor de la Capilla Real Granada, 1520-1522, que representa el bautismo de moriscas y moriscos. Del mismo modo, su uso era primordial en la consagración de la pila bautismal por medio de un diácono portando un hisopo, escena, según se ha señalado, presente en algunas pilas bautismales; en la bendición del agua bautismal y en la sagrada unción de los enfermos.

Palabra de origen árabe que significa recipiente con asa superior y giratoria, el acetre se utiliza para contener el agua bendita. Suele tener forma de cubo aunque la base no siempre es plana. Se acompaña del hisopo formado por un mango y una bola hueca, provista de una serie de agujeritos en su extremo, por donde sale el agua. En origen consistía simplemente en una ramita de tomillo o de hinojo y después se arbitró un mango de plata o marfil al que se fijaba un mechón de pelo de cerdo ${ }^{56}$. Se

53 J.M. CRUZ VALDOVINOS, Platería en la época de los Reyes Católicos, Madrid, 1992, pp. $157-158$.

54 G. MARIA, "Los vasos sagrados: el cáliz", http://infocatolica.com/blog/germinans.php/1110281003capitulo-39-los-vasos-sagrado

55 Durante la misa de consagración de los Santos Óleos a la hora del Gloria, se producía el prolongado sonido de las campanas. Este sonido comenzaba en algunos lugares antes de la misa. A completorio-dice Durando-sive a vespera qua Dominus traditus fuit, campanarum silentium inchoatur; alii ad primam huius quintae feriae et non ulterius pulsant campanas, fit tamen signum cum tabula. La tábula (crepitaculum, crótalo), de la cual habla Durando, era un instrumento de madera muy difundido en los claustros hasta los tiempos de Casiano, donde suplía al servicio de las campanas, entonces no muy generalizado. En particular, según las costumbres cluniacenses, se usaba sonar la tábula cuando un monje entraba en agonía (Tabula morientium) y cuando tenía lugar el lavatorio de los pies (ad mandatum). Es quizá de estos usos monásticos medievales de donde nace la costumbre de suspender en los días del triduo sagrado de la muerte del Redentor el sonido de las campanas y de substituirlo con el de los instrumentos de madera. M. RIGHETTI, op. cit., 1961, II, p. 252.

56 Una representación de las Cantigas (Cantiga 49, Códice Florencia), referida a la comunión de los enfermos, muestra a un capellán acompañado de un monaguillo portando el cáliz, la cruz, la campanilla y el acetre tal como prescribe la Partida I. El monaguillo de la Cantiga sujeta con su mano izquierda un 
considera como el acetre más antiguo (siglos IV-V) el de Túnez ${ }^{57}$. Uno de los acetres de mayor riqueza y significación, realizado en marfil y plata correspondiente al arte otoniano, fines del s. X, es el conservado en el Tesoro del Duomo de Milán (Fig. 6). Se cree procedente de la basílica de San Ambrosio donde debió ser usado por el comitente, el arzobispo Godofredo (974-979), para esparcir el agua lustral sobre un emperador otoniano, según la inscripción del borde: VATES AMBROSI GOTFREDVS DAT TIBI S(AN)C(T)E VAS VENIENTE SACRA(M) SPARGENDV(M) CESARE $\mathrm{LY}(\mathrm{M}) \mathrm{PH}(\mathrm{AM})^{58}$.

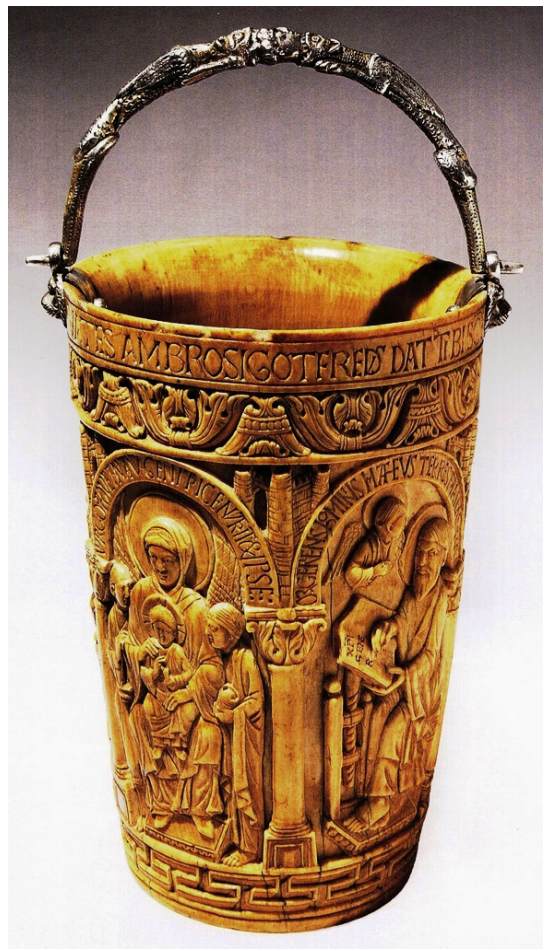

Fig. 6. Acetre del arzobispo Godofredo, fines del s. X. Tesoro del Duomo de Milán.

recipiente dorado y al parecer repujado provisto de asa que, García Cuadrado relaciona con uno conservado en el Instituto Valencia de Don Juan, realizado en cobre decorado con inscripciones y fechado en el s. XII. A. GARCÍA CUADRADO, Las Cantigas: El Códice de Florencia, Murcia, 1993, p. 399.

57 Vaso elíptico de plomo, con una aplicación de placas historiadas con símbolos y figuras, algunas con significado eucarístico y otras alusivas al martirio de las santas Perpetua y Felicidad, junto con otras figuras mitológicas. En la parte superior muestra una inscripción en griego, cita del profeta Isaías: "Sacaréis aguas con gozo".

58 R. BOSSAGLIA y M. CINOTTI, Tesoro e Museo del Duomo, I, Milán, 1978. Iconográficamente supone una exaltación de la Virgen dando de mamar al Niño. En cinco campos articulados por arquerías clásicas, se encuentra la Virgen con el Niño en trono, flanqueada por dos ángeles con incensario y acetre lustral, y las cuatro figuras de los evangelistas. A la derecha Juan y Marcos; a la izquierda, Mateo y Lucas, acompañados de sus símbolos. En sus libros abiertos se inscriben las palabras iniciales de los respectivos evangelios. La crítica es casi unánime al considerarlo obra milanesa. Agradezco el envío de la información. 


\section{Sagrada Unción de los enfermos o Extremaunción}

Junto con el Bautismo es un sacramento de vida que el cristiano recibe en el segundo momento crucial de su existencia: la enfermedad y el tránsito a la vida futura. Los Padres de la Iglesia han visto un anuncio anticipado del mismo en la narración de San Marcos (6, 12-14 y 17-18). Respecto a este sacramento, que acompaña a la penitencia, una primera cuestión a plantear es cómo denominarlo: "extremaunción" supone el final de la vida, en cuyo caso estaría destinado solo a los moribundos; en cambio, "unción de los enfermos" se refiere también a los que están gravemente enfermos, y, de hecho, la Iglesia celebraba este sacramento bajo dos formas, tanto para los enfermos como para los moribundos. Además, teniendo en cuenta el patrimonio litúrgico de las oraciones presentes en los antiguos sacramentarios, se observa que en ellas se invoca el restablecimiento físico de los enfermos y, por tanto la salud, expresando también gozo y agradecimiento a Dios por la curación obtenida ${ }^{59}$.

Este doble aspecto, que posibilita la repetición de la administración del sacramento, queda patente en la Epístola de Santiago $(5,14-16)$. El primer texto sobre la unción de los enfermos que cita expresamente el pasaje de Santiago es la carta de Inocencio I a Gubbio, obispo de Umbría, del año 416. Cesáreo de Arlés (†524) señala la importancia de que el enfermo reciba el Cuerpo y la Sangre de Cristo y enseguida se unja su cuerpo. Jamás menciona el peligro de muerte. Textos análogos aparecen en S. Eloy, obispo de Noyon ( $† 659)$. En el s. VII Beda el Venerable (672-735) al comentar las frases de Santiago, escribe que la práctica, todavía en vigor, muestra cómo los sacerdotes ungen con óleo consagrado a los enfermos y solicitan la curación con la oración. De sus palabras no se deduce que tal unción se realizase en la proximidad de la muerte o con un fin predominantemente espiritual. Del mismo modo, observa que, si el enfermo tiene pecados, obtendrá el perdón con la confesión mutua, si son veniales, y si, en cambio, son graves, sometiéndolos al juicio del sacerdote y a las obras de penitencia. Por tanto, considera la confesión como un complemento de la unción ${ }^{60}$. En la Primera Partida de Alfonso X, la Ley LXX dice que todos los cristianos deben recibir la Unción, que hacen a los enfermos y explicita que estos reciben tres bienes:

“...y por esta unción ganan tres bienes aquellos que la reciben. El primero que les da Dios mayor gracia para temerle, y para arrepentirse de los males que hicieron. El segundo que les mengua sus pecados... El tercero que los alivia de la enfermedad: les da fuerza para no temer la muerte y los conforta...".

Centrándonos en Occidente, en época carolingia, la unción de los enfermos experimenta un cambio profundo, explicitado en el triple plano; canónico, jurídico y teológico. Las Capitulares de Carlomagno (796 y 803) unen la unción de los enfermos con

59 Recogemos solo algunos títulos al respecto: E. COTHENET, "La guérison comme signe du Royaume et l'Onction des malades (Jc 5, 13-16), La Maladie et la Mort du chrétien dans la liturgie. Conférences Saint Serge: XXI semaine d'études liturgiques, Roma, 1975, pp. 101-125; A. BÉRARD, L'Onction des malades, sacrement de guérison ou de préparation à la mort?, París, 1996.

60 M. RIGHETTI, op. cit., 1961, II, p. 274. 
la penitencia y con la comunión (el viático) en la enumeración de las obligaciones de estado expresamente recordadas a los sacerdotes por el poder imperial. Aunque la finalidad penitencial del sacramento de la unción continúa durante mucho tiempo, ya a partir de los siglos X y XI, el óleo solo se administrará a los moribundos. Esto se traducirá en un cambio de denominación tomando el nombre de extremaunción.

Los escolásticos no pensaron en modificar lo más mínimo. Su interés se centró en analizar y fundamentar teológicamente la acción eclesial. Pedro Lombardo considera la unción de enfermos como sacramento de moribundos. Afirma que debe administrarse al final de la vida y la llama expresamente "extrema unctio". Le atribuye un doble efecto: perdona los pecados y alivia la debilidad corporal del enfermo. Buenaventura $(\dagger 1274)$ se expresa de manera similar; lo presenta como un sacramento para el trance de la muerte. Si no está en peligro de muerte no debe administrarse el sacramento. Tomás de Aquino (†1274) escribió dos tratados completos sobre la unción de los enfermos; uno en su Comentario a las Sentencias, y el otro en la Summa contra gentiles. También la llama "ultima unctio". No obstante, considera la posibilidad de que el enfermo se cure, y afirma que puede repetirse si cae en la misma situación. Concibe la extremaunción como sacramento de curación, pero piensa especialmente en curación espiritual. Juan Duns Scoto $(\dagger 1308)$ restringe el círculo de los que pueden recibir la extremaunción, quiere que se espere al estado de inconsciencia. El Concilio de Trento (1545-1563), Sesión XIV, añade un matiz: declara que esta unción debe otorgarse a los enfermos, especialmente a los que están tan peligrosamente afectados que parecen próximos a la muerte; por eso se llama sacramentum exeuntium ${ }^{61}$.

La celebración del sacramento, llevada a cabo por el sacerdote, precisa de un determinado ritual. Entre los elementos que lo integran hay que tener en cuenta: la imposición de manos por los presbíteros de la Iglesia, el contenido de la fórmula, la proclamación de la palabra de Dios, el rito de la aspersión con agua bendita que recuerda y renueva el bautismo y el momento de ungir al enfermo con el óleo santificado por la bendición de Dios ${ }^{62}$. La unción se materializa pasando el óleo por la frente y las manos del enfermo, pero nada prohíbe que se aumente el número de unciones o se cambie el lugar. Ya en el s. IX se enumeran las partes del cuerpo que deben ser ungidas, imponiéndose los rituales que prescriben siete unciones: ojos, oídos, nariz, labios, riñones (pecho), manos y pies. Estos rituales aparecen en Francia y Alemania y se consolidan en Roma durante los siglos XII y XIII. Del mismo modo, en la Primera Partida de Alfonso X se habla de siete puntos del cuerpo ${ }^{63}$. Entre las numerosas

61 Archiprêtre E. MÉLIA, “Le sacrement de l'onction des malades dans son développement historique et quelques considérations sur la pratique actuelle", La Maladie et la Mort du chrétien dans la liturgie, op. cit., pp. 193-228; "Sacramento de la unción de los enfermos", http://es.tanatopedia.net/index.php/Sacramento de_la_unci\%C3\%B3n_de_los_enfermos (acceso 27/02/2013); M. NICOLAU, La unción de los enfermos, Mādrid, 1975; La Unción de los enfermos, Cuadernos Phase 3, Barcelona, 1988; y R. MESSINA, La unción de los enfermos, Madrid, 2002.

62 Ordo Unctionis Infirmorum eorumque pastoralis curae, 1972, 5.

63 Título III, Ley LXIX: "Del quinto sacramento, que es la Unción postrera... Y esta unción la debe hacer en siete lugares del cuerpo; en los ojos, en las orejas, en las narices, en la boca, en las manos, en los pies, en los lomos de los varones, e a las mujeres en los ombligos: diciendo aquellas palabras que suelen decir a este oficio. E por esto lo hacen en estos lugares, porque son los miembros con que mas pecan los hombres". 
representaciones que nos ilustran sobre su administración, a modo de ejemplo, recordamos el tríptico de los Siete Sacramentos, de Rogier van der Weyden (Koninklijk Museum voor Schone Kunsten, Amberes, Bélgica) (Fig. 7). En él queda plasmado en la tabla izquierda el Bautismo y en la derecha la Extremaunción ${ }^{64}$.

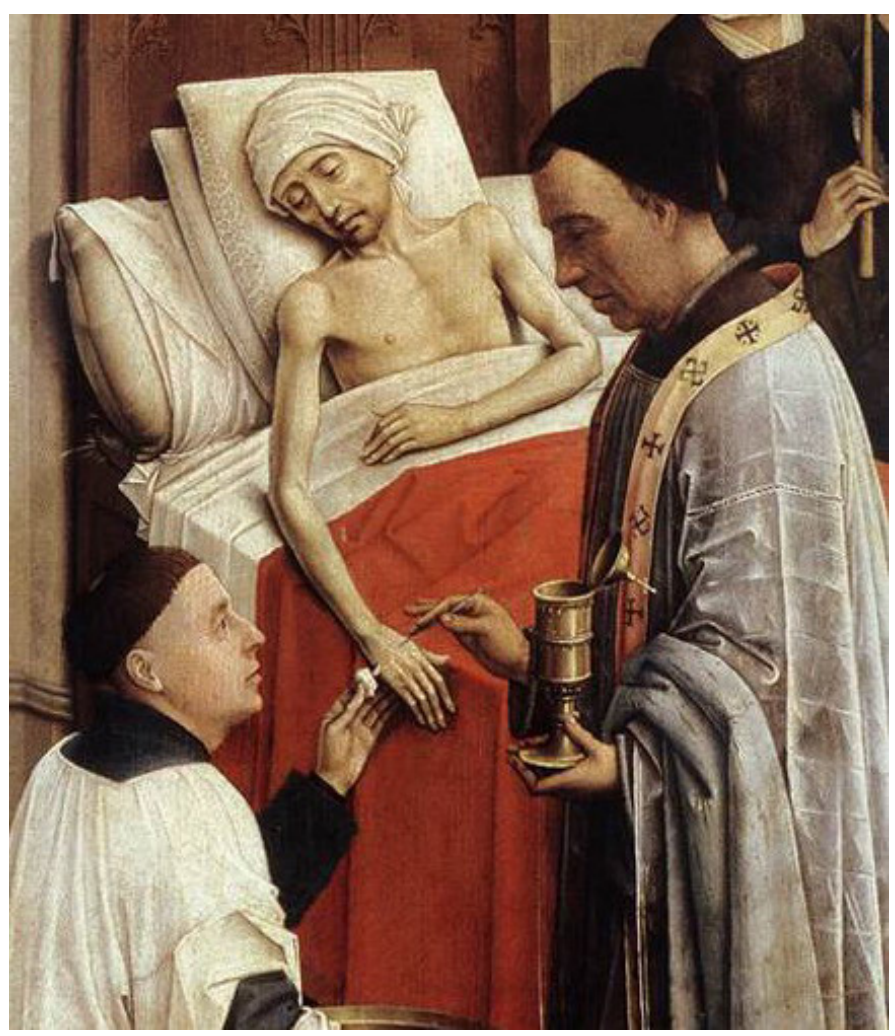

Fig. 7. Rogier van der Weyden, Tríptico de los Siete Sacramentos. Koninklijk Museum voor Schone Kunsten, Amberes, Bélgica.

Además, Cristo, al mismo tiempo que sana el cuerpo, libera de los demonios, perdona los pecados y saca de la angustia y la marginación en el momento supremo. En el Levítico $(5,17-26 ; 10,16-20)$, se alude al pecado y a su reparación mediante el sacrificio. En la enfermedad, Jesús enseña la verdad sobre la relación poder del demonio-pecado-enfermedad. No niega que actúe la fuerza de Satanás, pero afirma que el poder de Dios interviene contra las fuerzas del mal, según refiere Mateo $(12,28)$. El IV Concilio de Letrán (1215) al relacionar la enfermedad con el pecado impuso al médico la obligación de advertir a sus pacientes en trance de muerte la proximidad

64 El Tríptico de los Siete Sacramentos fue donado por el obispo de Tournai Jean Chevrot (1436-1460), uno de los principales consejeros de Felipe el Bueno, cuya heráldica figura en el mismo, a la colegiata de San Hipólito de su ciudad natal, Poligny. 
de esta y la necesidad de acudir al confesor. Así pues, todo hombre recibe ayuda para lograr su salvación obteniendo nuevas fuerzas contra las tentaciones del maligno y la desazón que provoca la cercanía de la muerte. Todo esto queda perfectamente recogido en los grabados del Ars Moriendi, aparecidos en el s. XV, en el entorno del Concilio de Constanza (1414-1417), en los que se plasma el momento crucial del moribundo que se ve sometido a numerosas tentaciones, finalmente superadas por intervención divina ${ }^{65}$.

\section{El Viático}

La administración del Viático supone la participación en la Eucaristía como alimento para viajar a la eternidad. En este sentido, es sumamente curiosa la práctica de enterrar a los muertos con la Sagrada Forma. Un uso bastante singular, que Ponce de León remonta a la costumbre pagana de depositar una moneda en la boca de los muertos para que pudieran pagar su pasaje al barquero de Cocito. Los cristianos, como en otras ocasiones, conservarían la forma pero cambiarían el espíritu, reemplazando la moneda material por la moneda celeste que podía pagar la redención de sus pecados. Esta idea que recoge Corblet, sin embargo, no la comparte. Para él, el motivo más plausible es que cuando los penitentes y excomulgados morían antes de haber tenido tiempo de una reconciliación, se los enterraba con hostias no consagradas, para mostrar que la Iglesia los reintegraba de alguna manera en su seno, restituyendo el derecho de ofrecer oblaciones, derecho que solo corresponde a los fieles. Según él, de los textos que se citan al respecto, se deduce esta interpretación. Con el paso del tiempo, este uso primitivo se desnaturalizó en algunas localidades y fueron hostias consagradas las que se depositaron en las tumbas. Las actas de numerosos concilios no dejan duda al respecto. Esta costumbre de enterrar la Eucaristía con los que no habían podido recibirla en su última hora fue prohibida en numerosas ocasiones: III Concilio de Cartago (397); Concilio de Auxerre (578), etc. Como es habitual, las reiteradas prohibiciones indican que la práctica seguía vigente ${ }^{66}$.

El orden en que se establece la administración de estos sacramentos no siempre ha sido unitario aunque, al parecer, lo idóneo debería ser la Penitencia, la Unción y la Eucaristía bajo forma de Viático que, en cierto sentido, reproduce el de los sacramentos de la iniciación cristiana: Bautismo, Confirmación y Eucaristía ${ }^{67}$. Así pues, la comunión extra misa se contempla en casos de necesidad para los enfermos

65 La bibliografía sobre el Ars Moriendi es muy abundante por lo que recogemos solo algunos títulos: M.K. O'CONNOR, The Art of dying Well. The Development of the Ars Moriendi, Nueva York, 1966; A. TENENTI, La vie et la mort à travers l'art du XV siècle, París, 1983; y E. RUIZ GARCÍA, "El Ars Moriendi: una preparación para el tránsito", N. ÁVILA SEOANE, M.J. SALAMANCA LÓPEZ y L. ZOZAYA MONTES (eds.), IX Jornadas Científicas sobre Documentación: la muerte y sus testimonios escritos, Madrid, 2011, pp. 315-344.

66 L'Abbé J. CORBLET, op. cit., $1^{\text {er }}$ artículo, pp. 56-69. La mención de Ponce de León, sin duda, se refiere a Basilio Ponce de León (1570-1629), teólogo, canonista, poeta y escritor agustino, sobrino de Fray Luis de León.

67 Ordo Unctionis..., op. cit., 30. 
y moribundos. Aunque no se poseen testimonios anteriores al s. III, no se puede poner en duda que esta práctica se remonta a los primeros tiempos de la Iglesia. La comunión únicamente se distribuía durante la misa y las especies consagradas solo se reservaban para los enfermos. Los sacerdotes debían tener siempre la Eucaristía presta para llevársela y se tenían que encargar de renovarla para que las especies no se estropeasen.

Después de consagradas las hostias, el sacerdote las toma de la patena y las pone en una especie de cajita, de oro, plata o madera, según la riqueza de la iglesia, que ha recibido nombres diversos; píxide, ciborio, custodia, etc. En seguida, a fin de que no quede ningún resto de partículas sobre la patena, la limpia con una especie de esponja extremadamente exprimida. El receptáculo, cerrado, se envuelve en un trozo de tela y se guarda. Si se solicita el Santo Sacramento para algún enfermo, el sacerdote acompañado de los diáconos y precedido de otras personas que portaban antorchas encendidas, toma el envoltorio en que está encerrado el recipiente y lo lleva con respeto, a veces en una bolsita colgada del cuello, el portaviático. Tras haber confesado al enfermo y hecho las oraciones acostumbradas, le administra el sacramento. Después, vuelve con la misma ceremonia que ha venido y deja el ciborio en su lugar.

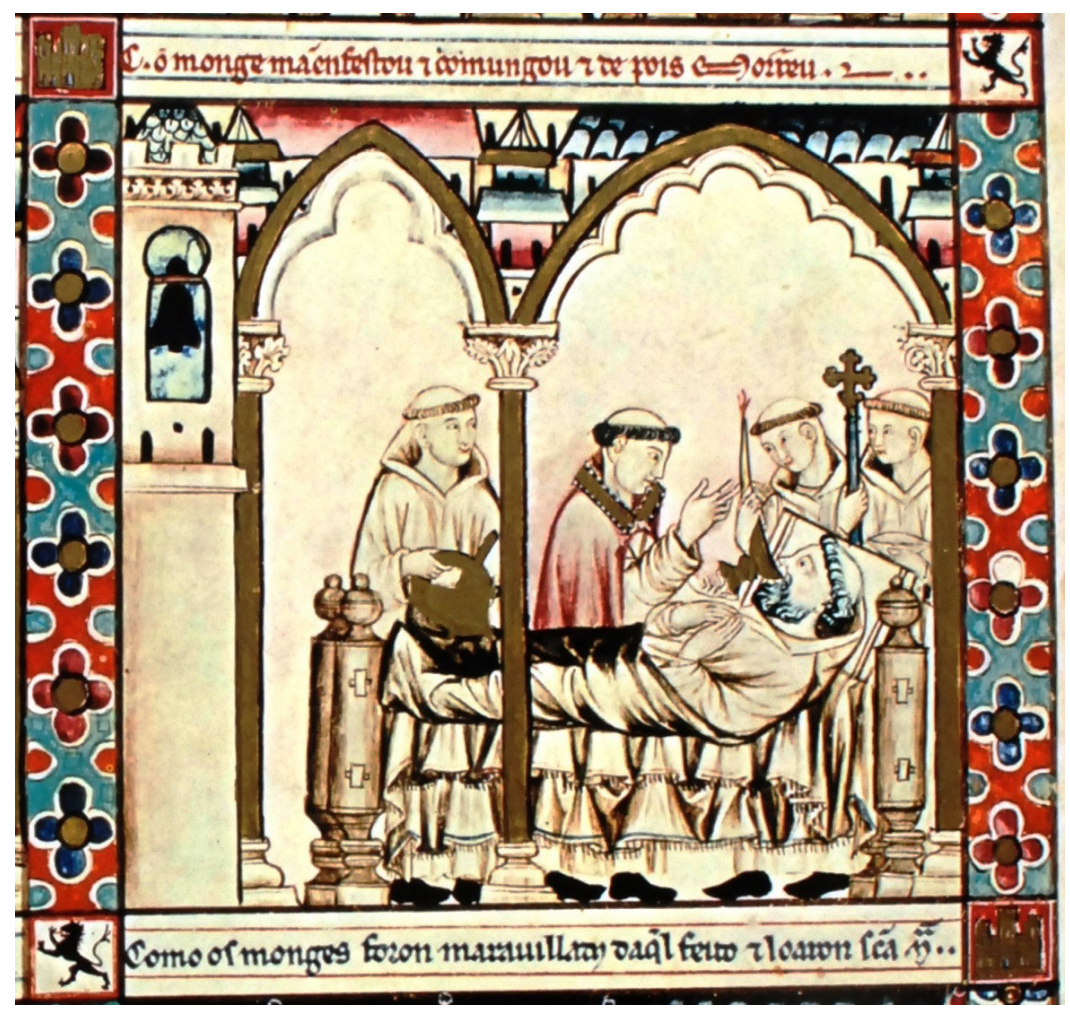

Fig. 8. "Muerte de un monje", Cantiga 56d, Códice Rico de las Cantigas de Santa María (RBME, Ms. T-I-1). 
Ahora bien, ¿se llevaba la comunión a los enfermos bajo las dos especies o solamente bajo la del pan? La reserva eucarística que, durante mucho tiempo, pudo cada uno guardar en el sagrario doméstico, se conservaba, únicamente, en una sola especie: el pan consagrado, Sin embargo, no podemos negar que, en muchos casos, se llevase al enfermo también vino consagrado. Numerosos testimonios hablan de la última comunión bajo las dos especies. Así se aprecia en la Cantiga 49-c del Códice de Florencia o en la Cantiga 56 (Códice Rico de El Escorial) (Fig. 8), donde un monje enfermo bebe del cáliz, mientras otros cuatro monjes rodean su lecho. Entre los objetos que portan se puede reconocer la cruz, un aspersorio y un cirio. De todos ellos este último, encendido, nunca falta como puede observarse en la Cantiga 123 (Códice Rico, El Escorial). Su misión era simbolizar la luz de la fe y ahuyentar a los diablos que se llegaban al moribundo para arrebatarle el alma ${ }^{68}$.

Los vasos que contenían la reserva eucarística para los enfermos se custodiaban en las sacristías o en pequeños armarios dispuestos en el muro o en uno de los pilares de la iglesia, cerca del altar. A menudo, estos armarios recibían el nombre de sacraria. Rupert de Deutz en el s. XII, al relatar el milagro por el cual se había preservado en el incendio de su monasterio, el vaso de madera que contenía la reserva eucarística, nos enseña que estaba depositada en un nicho practicado en el muro, conforme a la costumbre seguida en su tiempo. Durante la celebración de la Misa, en algunos países, especialmente Francia, las santas especies eran encerradas en una píxide o una paloma suspendidas por cadenas a un báculo eucarístico, o simplemente colgadas por encima del altar. En la novena centuria una carta del papa León IV $(† 855)$ decretando que la Eucaristía debía conservarse en una píxide sobre el altar, oficializó su existencia y su lugar en la iglesia ${ }^{69}$.

El origen de píxides, ciborios, copones, etc. se remonta a la antigüedad grecoromana, cuando pequeñas cajas o cofres decorados se utilizaban por las familias para guardar diferentes objetos preciosos. Originalmente fabricados en madera de boj, en griego puxos, de ahí el nombre de pyxis en latín, después estos cofres fueron, a menudo, realizados en marfil. En tiempo de las persecuciones, los primeros cristianos, para disimular y proteger las hostias consagradas, recurrieron a estas píxides que, además, se podían transportar fácilmente para dar la comunión a los impedidos o a los moribundos. A partir del s. IV, después del reconocimiento del cristianismo como religión oficial en el Imperio romano, motivos cristianos y no paganos las decoraron ${ }^{70}$.

La utilización de estas pequeñas reservas eucarísticas para llevar la comunión a los moribundos se perpetuó en la Edad Media. Como materiales, después de la madera, la hojalata y el cartón se emplearon junto al vidrio, la fundición, el alabastro, el mármol e incluso el estaño. Sin embargo, estas materias no se consideraron bastante bellas o bastante sólidas y algunos inventarios medievales las mencionan hechas en ágata, berilo, onyx y otro tipo de piedras. A menudo, se empleó el cobre desprovisto

68 F. MARTÍNEZ GIL, La muerte vivida: muerte y sociedad en Castilla durante la Baja Edad Media, Madrid, 1996, p. 37.

69 "Decretales del papa León IV”, J.-P. MIGNE (ed.), Patrologia latina, CXV, col. 677.

70 S. CAUDRON, "Pyxides", Corpus des Émaux Méridionaux. L'Apogée 1190-1215, t. II, París, 2011, pp. 168-169. 
de todo ornamento, tal como se recoge en los estatutos sinodales de Jean, obispo de Lieja, publicados en 1287. Los concilios del s. XIII y los rituales publicados desde esta época, permiten emplear el marfil, el cobre esmaltado y a veces el simple latón, pero ponen casi siempre la plata en primer lugar e indican que era la materia que se debía usar principalmente ${ }^{71}$.

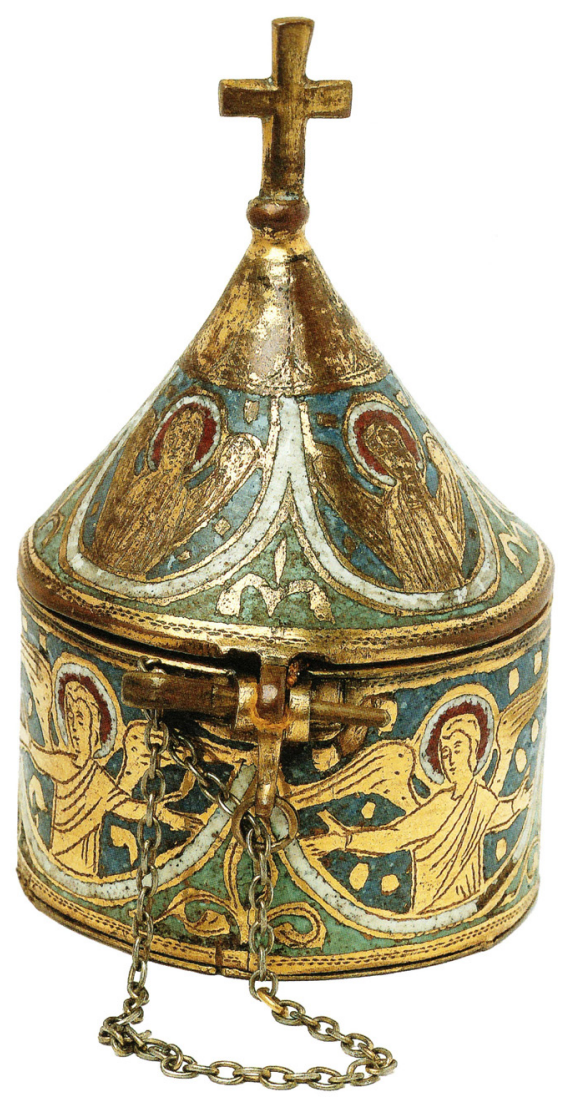

Fig. 9. Píxide, c. 1230, Esparza de Galar. Museo de Navarra, Pamplona.

Entre las píxides más tempranas conservadas podemos destacar la de Pesaro, correspondiente al s. IV, realizada en marfil, de forma circular articulada por herrajes ${ }^{72}$. Ya en la Alta Edad Media es frecuente la forma de una cajita cilíndrica con una cubierta cónica que hará fortuna posteriormente, de modo especial en piezas salidas de talleres lemosines, cuya producción se desarrolló principalmente gracias al papa

71 E. RUPIN, op. cit., 1977, pp. 202-203.

72 F. MONFRIN, "La guérison du serviteur (Jn. 4, 43-54). Une nouvelle interprétation des sarcophages de Bethesda", Mélanges de l'École Française de Rome. Antiquité, 97, 2 (1985), p. 985, n. 20. El hecho de que la escena representada se haya identificado con la resurrección de la hija de Jairo puede hacer pensar que se trata de un milagro de resurrección, lo que implica que más que un enfermo es un muerto. 
Inocencio III (Fig. 9). Presentan casi siempre la misma forma, pero la variedad en la decoración es infinita. El interior, generalmente dorado, es cilíndrico y a veces se encuentra provisto de una cubeta que disminuye la profundidad ${ }^{73}$. De hecho, en los siglos XV-XVI los Sínodos y los Rituales recomiendan tener dos tipos de píxides: una mayor, que debe permanecer en el sagrario, y otra más pequeña para llevar el viático a los enfermos.

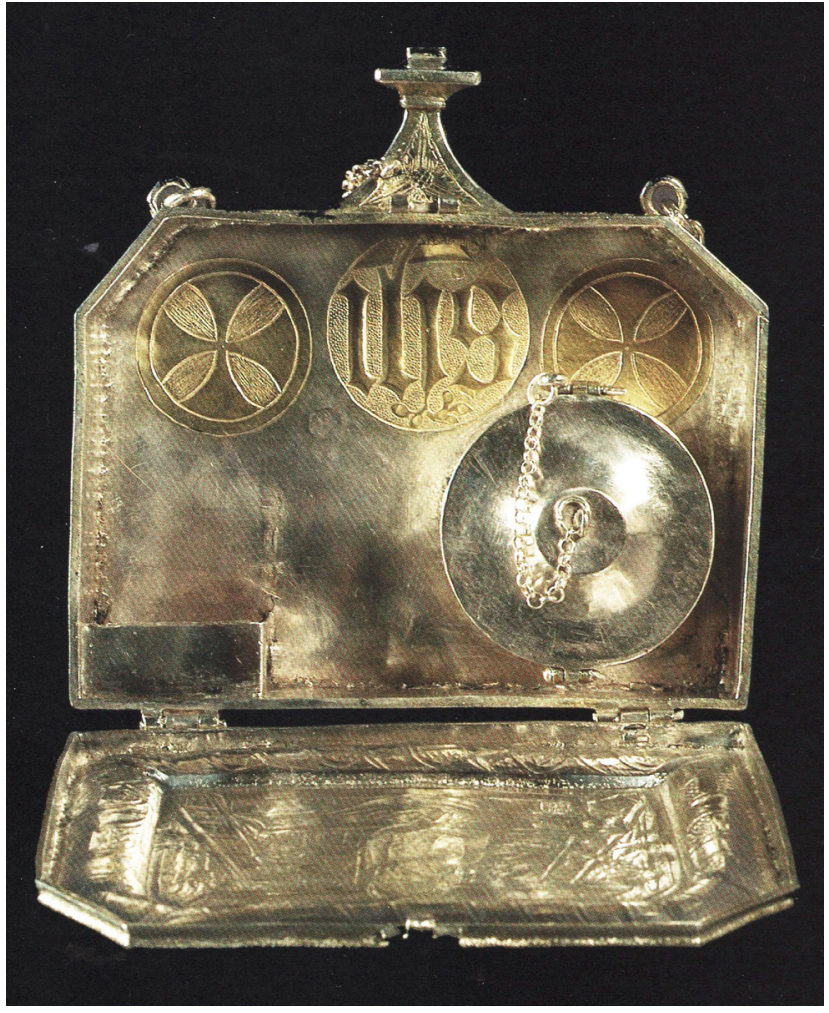

Fig. 10. Portaviático con crismera, fines del s. XV. Iglesia parroquial de la Asunción de María de Catí, Castellón.

Ahora bien, no siempre las píxides presentaban esta forma, pues conocemos también la existencia de pequeñas cajitas de forma circular como las que se conservan en los Musées Royaux d'Art et d'Histoire de Bruselas, correspondientes a talleres mo-

73 M.L. MARTÍN ANSÓN, op. cit., 2011. Algunas de estas píxides están rematadas por una cruz, otras simplemente por una bola. La ornamentación es variada y se repite sobre la cubierta y sobre el cuerpo de la caja. En numerosas ocasiones, se suspendían por encima del altar, al igual que las palomas eucarísticas, encerradas en un pabellón de tela. Reposan sobre su base, simulando una torrecilla coronada por una cubierta cónica, que se articula a la caja por una charnela. Si en las parroquias pobres no eran más que simples vasos de cobre o latón; en las catedrales, en las ricas abadías, en las iglesias de las ciudades, su superficie se llenaba de decoración. 
sanos, fechables en los siglos XIII-XIV ${ }^{74}$. Además, en ocasiones, muchos sacerdotes guardaban la Hostia en un simple corporal o en una bolsita, portaviático, e incluso entre las hojas del Breviario.

Con el paso del tiempo las formas fueron complicándose, creándose auténticos estuches donde se incluían también los óleos. Así podemos destacar, a modo de ejemplo, un portaviático con crismera, atribuido a Juan Santalínea, de fines del s. XV, de plata sobredorada, en la iglesia parroquial de la Asunción de María de Catí (Castellón) (Fig. 10) ${ }^{75}$.

No podemos cerrar esta exposición sin, al menos, aludir a la presencia de milagros vinculados a la administración del viático. Ciertamente los prodigios eucarísticos son muchos y de muy diversa índole, dado el culto y la veneración adquiridos por la Eucaristía. Recordemos uno íntimamente relacionado con la comunión extra misa, cuya conmemoración continúa en pleno vigor. Se trata del acontecimiento ocurrido en Alboraya en 1348, cuando las Sagradas Formas fueron recuperadas por los peces tras haber desaparecido, durante una tormenta, el portaviático que el sacerdote llevaba al cuello. En la narración están presentes todos los ingredientes propios de la época ${ }^{76}$.

\footnotetext{
74 Musées Royaux d'Art et d'Histoire. Art Chrétien jusqu'à la fin du Moyen Âge, Bruselas, 1964, 183, p. 44, $4,5 \mathrm{~cm}$. Adquiridas a la colección Hagemans, 1861. Realizadas en cobre dorado y grabado, su cubierta plana está decorada una con una rosácea y la otra con guirnaldas alrededor de una cruz calada.

75 J.L. GIL CABRERA, "Portaviático con crismera", La Llum de les Imatges, Generalitat Valenciana, 2005, pp. 272-273. Es una cajita de forma rectangular con la representación de Cristo Varón de Dolores emergiendo del sepulcro, entre emblemas de la Pasión. Va provista de una cadena de plata para ser colgada del cuello del presbítero cuando se disponía a llevar el viático. En su interior se observa un depósito circular con tapadera cónica para el Corpus Domini, a la izquierda, y a su derecha, un apartado rectangular para encajar el Oleum Infirmorum.

76 M. PEPIN, Las ermitas de Valencia, I, Valencia, 1996, pp. 34-38.
} 